\title{
The public impact of impacts: How the media play in the mass extinction debates
}

\author{
Steve Miller \\ Department of Science and Technology Studies, University College London, Gower Street, London WC1E 6BT, UK
}

\begin{abstract}
"Mass media" presentations of the dinosaurs and their co-inhabitants have been around for some 200 years. The question of what exterminated the dinosaurs and allowed mammals to take their leading place on Earth has a similarly lengthy history in the scientific arena and in public. However, there are amazingly few communication studies of the debates around mass extinctions and impacts. Those that do exist have picked up on the fact that these debates involve scientists from several disciplines, scientists who are often unused to reading each other's research. Under these circumstances, more public or leading journals play a key role, not only in getting ideas out into the public arena, but in informing scientists across disciplinary boundaries. "Normal" communication processes, in which articles in peer-reviewed journals inform the scientific community and "simplified" versions may trickle out to the public via the mass media, become more complex.

The dramatic impact answer to the question of the death of the dinosaurs seems to have attracted limited media attention at the time, confined to the "elite" newspapers. This paper analyzes the newspaper coverage of the death of the dinosaurs during the period from 1980 to 2008 . I find that the period from 1991 to 1995 was critical in terms of changing public perceptions, insofar as they are determined/reflected in articles in general newspapers. I argue that the "Great Crash of 1994," when Comet Shoemaker-Levy 9 collided with the giant planet Jupiter, played an important role in propelling the impact scenario for the death of the dinosaurs into the (mass) public eye, and that the news value co-option was important in this process.
\end{abstract}

\section{INTRODUCTION}

"Two proposals that involved catastrophes that enveloped the Earth in sun-shading debris have been advanced to account for past episodes of widespread extinction and climate change. One was a direct hit on the Earth by an asteroid, causing an explosion whose debris cut off all or most sunlight for several years. This could explain the extinction of the dinosaurs and numerous other creatures some 65 million years ago" (Sullivan, 1980, p. C3).

"Just about every astronomer in the world will be looking at only one place this coming July - the planet Jupiter. It's going to be the most important astronomical event for centuries, and the most eagerly awaited. In July, a massive speeding comet will smash into Jupiter, unleashing the most powerful forces seen since our local star, the Sun, was born" (Turner, 1994).

Miller, S., 2014, The public impact of impacts: How the media play in the mass extinction debates, in Keller, G., and Kerr, A.C., eds., Volcanism, Impacts, and Mass Extinctions: Causes and Effects: Geological Society of America Special Paper 505, p. 439-455, doi:10.1130/2014.2505(24). For permission to copy, contact editing@geosociety.org. () 2014 The Geological Society of America. All rights reserved.

Gold Open Access: This chapter is published under the terms of the CC-BY license and is available open access on www.gsapubs.org. 
Separated by almost 14 years, these two quotations deal with the first widely accepted (if strongly contested) theory to account for the demise of the dinosaurs and their fellow inhabitants of Earth some 65 m.y. ago at the end of the Cretaceous Period, and an unparalleled astronomical event that did much to lend credence to that theory amongst the wider scientific community and the general public at large. On 6 June 1980, Luis and Walter Alvarez and their coworkers Frank Asaro and Helen Michel published an article in the prestigious, interdisciplinary journal Science, claiming that an iridium-rich layer of clay found at the Cretaceous-Tertiary boundary was the result of a $10-\mathrm{km}-$ diameter asteroid hitting Earth and creating climatic conditions that caused the mass extinction observed at that time (Alvarez et al., 1980). The first quotation above is science journalist Walter Sullivan's report about this paper in the New York Times a few days later. (Note that this had been foreshadowed by coverage of the 1979 meeting of the American Geophysical Union, when this theory was presented there.)

On 26 March 1993, comet-hunters Caroline and Eugene Shoemaker and their colleague David Levy sent out an International Astronomical Union telegram announcing that, 3 days earlier, they had discovered a "squashed comet" that appeared to be orbiting Jupiter (International Astronomical Union, 1993). Over the next couple of months, further observations produced an orbit reliable enough to demonstrate that (1) Comet Shoemaker-Levy 9 (SL9) was indeed orbiting Jupiter, (2) that in July 1992, it had undergone a close encounter with Jupiter that had caused it to fragment in 20 pieces (giving the "squashed" appearance first noted in the low-resolution images taken by the Shoemakers and Levy), and (3) that in July 1994, the comet would actually crash into the giant planet.

The second quote above is from British Broadcasting Corporation $(\mathrm{BBC})$ television presenter Anthea Turner giving a headsup to British 10 years olds that Jupiter was the place to watch that coming summer. Her report came direct from the Barringer Crater in Arizona and went out on the children's program Blue Peter, one of the UK's most watched television shows by both preteens and their parents. Toward the end of her piece, Turner opined: "Some scientists believe that it was a comet that hit the Earth, causing a climatic change that resulted in the extinction of the dinosaurs." SL9 and the death of the dinosaurs were linked. This paper looks at original data from general newspaper articles to see how this worked out in practice.

\section{INTERDISCIPLINARY SCIENCE AND THE PUBLIC SPHERE}

Dinosaurs have fascinated the public ever since scientists first attempted to put flesh on their fossilized bones in the nineteenth century. Victorian promenaders could gaze with wonder at Benjamin Waterhouse Hawkins' reconstructions of them in the Crystal Palace Park in South London from the mid-1850s onwards. These life-sized statues-despite their anatomical imperfections that reflected the state of knowledge of the time and the disputes between paleontological giants of the stature of Richard Owen and Gideon Mantell-remain treasured features of the park today. (Visitors to New York might also have had the same pleasure had Waterhouse Hawkins not run afoul of William Boss Tweed in the 1870s, when he was working on models for Central Park [see Bramwell and Peck, 2008].)

Understanding the dinosaurs and their fellow creatures always was an interdisciplinary issue, although their study dates back to a time when the boundaries between individual scientific disciplines-and, indeed, between science and general culture/ knowledge-were still in the process of crystallizing (Young, 1985; Yeo, 1993). Tensions abounded-geologists demanding "deep time" to account for measured rock formations to accumulate and erode according to Charles Lyell's (1830) principle of uniformitarianism were faced with Lord Kelvin's estimate of the age of Earth of a few tens to a hundred million years, based on principles of (astro)-physics (Burchell, 1975). Kelvin was sufficiently scary that Darwin withdrew his estimate of 300 m.y. for the time taken for the "denudation of the Weald" (Darwin and Costa, 1859, 2009).

Scientific disputes were fought out in the public sphere: in meetings of the British Association for the Advancement of Science and (later) the American Association for the Advancement of Science or in the pages of The Athenaeum or Macmillan's Magazine (e.g., Broks, 2006; Fyfe and Lightman, 2007; Lightman, 2007; Rudwick, 1985), and from the dinner parties of the Victorian upper classes to the meetings of the working class Mechanics Institutes (Secord, 2000), until such time as the sheer volume of science and its increasing specialization meant that such disputes were no longer comprehensible to the wider public (Young, 1985). At that point, they tended to disappear into "specialist" journals such as Nature (an 1869 split off from Macmillan's Magazine) and the burgeoning scientific societies. In the case of the dinosaurs, their public display came just prior to this period of change. So controversy over the posture of iguanodon-bird-like according to Owen; lizard-like according to Mantell-was (and is still) publicly visible in the two statues made by Waterhouse Hawkins for Crystal Palace Park. (Neither statue has the thumb-spike right, however; it is firmly attached to both noses.)

By the time the Alvarez team were at work, scientific disciplines were much more firmly entrenched than a century earlier. Their 1980 paper cut across several of these. This is evident from the summary alone, which clearly covers matters geological, astronomical, and paleontological (see Fig. 1). The themes outlined in the summary are expanded in the main article, with evidence deduced from all three disciplines as well as modern biological studies. The paper was "politically" timely: Many scientists were looking into the possible effects of nuclear war, in particular, the climatic effect known as a "nuclear winter" that would arise from the dust and gas generated by massive fusion explosions; the asteroid impact theory relied on mechanisms akin to "nuclear winter" for its killing power (Glasstone, 1983; Turco et al., 1983). 
The three science disciplines already mentioned each come with their own prevailing (but not necessarily exclusive) "ideologies." Geology, as already mentioned, has a strong allegiance to the uniformitarianism proposed by Lyell to break the "NeptunistPlutonist" rivalries of the previous century (Lyell, 1830; Davy, 1805/1980). Paleontology draws heavily on the gradualism of Darwin's Origin of Species (Darwin and Costa, 1859/2009). Catastrophism and extreme events are to the fore amongst the astronomical community-What could be more "catastrophic" than the Big Bang origin of the universe? Standard theories of the formation of the solar system, such as the "Nice model," involve multiple and massive impacts, including such epochs as the Late Heavy Bombardment some 3.95 b.y. ago (Gomes et al., 2005).

Standard accounts of how scientific results are popularizeda process that the French call vulgarisation and the Spanish divulgacion, with slightly different nuances-tend to have a somewhat linear structure. Upstream in the process, there are the peer-reviewed journals, in which well-behaved scientists test out their ideas on their colleagues and await their approval. If they are sufficiently interesting, these ideas may be channeled downriver via the media, eventually making it into the muddy delta of the public sphere. This journey from scientific purity to public imperfection and oversimplification is one that allows the scientific community to exercise maximum control over what gets "out" and how (Hilgartner, 1990).

However, communication scholar Bruce Lewenstein (1995) has demonstrated that where the science crosses disciplinary boundaries, and particularly where big claims are made with important implications, this neat, linear process just does not work. In its place, Lewenstein proposes a "web" of communication channels, not least of which are the mass media, and through which the wider scientific community, as well as the general public, are informed of the latest developments. Lewenstein's web model arose out of his study of the "cold fusion" debates of the late 1980s, in which Stanley Pons and Martin Fleischmann claimed to have generated nuclear fusion in a simple electrochemical cell. Lewenstein's model was independently supported by Frank Close, one of a number of physicists who debunked cold fusion. Close claimed that-since Pons and Fleischmann refused to publish their data in peer-reviewed journals - other scientists were reduced to photographing purported plots of neutron emission on their television screens as they watched the evening news (Close, 1990). Lewenstein's web model (1995) has also been applied to other areas, such as "life from space" (Gregory, 2003) and general physics (Mellor, 2003).

One scholar who has looked seriously at the public impact of the impact hypothesis for the Cretaceous-Tertiary extinctions is Elisabeth S. Clemens $(1986,1994)$. She points out that those involved in the various debates have been brought together as a result of their support for or opposition to (or even their wish to modify) a particular theory, rather than because they all belong to the same scientific discipline, adding:

Broad-ranging interdisciplinary science strains the ability of personal and professional ties to promote consensus over the definition of problems and the criteria for proof. Under such conditions, considerable light may be shed on procedures and criteria that usually go unexamined (Clemens, 1986, p. 425).

Clemens demonstrated the importance of the general science journals such as Science and Nature in advancing the discussion. These two general journals accounted for 117 (nearly a quarter) of the 498 citations to the Alvarez et al. paper (1980) that occurred during the 1980s in the 130-plus journals that she looked at. Moreover, nearly 140 articles discussing impacts and extinctions were published in the American popular (science) press, including publications such as Scientific American and The New Yorker, over the same period. Clearly, the impact hypothesis was making its mark well outside of disciplinary scientific journals, and involving a wide range of scientists and
Summary. Platinum metals are depleted in the Earth's crust relative to their cosmic abundance; concentrations of these elements in deep-sea sediments may thus indicate influxes of extraterrestrial material. Deep-sea limestones exposed in Italy, Denmark, and New Zealand show iridium increases of about 30,160 , and 20 times, respectively, above the background level at precisely the time of the Cretaceous-Tertiary extinctions, 65 million years ago. Reasons are given to indicate that this iridium is of extraterrestrial origin, but did not come from a nearby supernova. A hypothesis is suggested which accounts for the extinctions and the iridium observations. Impact of a large earth-crossing asteroid would inject about 60 times the object's mass into the atmosphere as pulverized rock; a fraction of this dust would stay in the stratosphere for several years and be distributed worldwide. The resulting darkness would suppress photosynthesis, and the expected biological consequences match quite closely the extinctions observed in the paleontological record. One prediction of this hypothesis has been verified: the chemical composition of the boundary clay, which is thought to come from the stratospheric dust, is markedly different from that of clay mixed with the Cretaceous and Tertiary limestones, which are chemically similar to each other. Four different independent estimates of the diameter of the asteroid give values that lie in the range $10 \pm 4$ kilometers.
Figure 1. Summary of the $1980 \mathrm{Sci}$ ence article by Alvarez, Alvarez, Asaro, and Michel. The section shaded in blue is mainly geology, the section shaded in red is mainly astronomy, and the section shaded in green is mainly paleontology/geology. 
individuals with a more amateur interest in science (Clemens, 1994). In interdisciplinary debates, the wider public sphere has to be addressed by those arguing for and/or against particular points of view. To extend the work of Clemens on the high-profile general science journals, I have chosen to look at Nature for the three decades from 1979 onwards: There is a plausible - though undocumented-argument that Luis Alvarez's associations with Science may have influenced that journal's early stance on the impact theory; I have had private and convincing correspondence with the editorial staff of Nature indicating that, at the time, no such influence could have been brought to bear there.

Figures 2 and 3, respectively, show coverage for the term "dinosaur" in the "Research" section (including "Articles," "Letters to Nature," and "Scientific Correspondence") and "News" section (including "News and Views") of Nature for the 30 years covered by this study. This is wider than Clemens' original search, but it is intended to give some background to those articles that deal either mainly or in passing with extinction issues. Overall, this search of Nature produced 804 articles, of which 208 came under the "Research" heading and 276 under "News," after some "spuriously selected" articles from the automated search were manually rejected. Thus, over half of the total Nature coverage of "dinosaur" issues was analyzed. For both sections, articles were characterized as "pro" impact theory, "anti" impact theory, "balanced," or "other" if they mentioned dinosaurs but made no comment about extinction. Interest in dinosaurs is clearly much greater in both sections analyzed in the second half of the period analyzed than in the first.

For the "Research" section of Nature, interest in the extinction of the dinosaurs is almost totally confined to the first half of the sample, however. Up to 1994, there were 12 articles that were clearly in favor of the Alvarez et al. (1980) impact theory (or variations on it), and nine against. There were five research articles characterized as "balanced" up to 1994. After 1994, there is one balanced in 2001 and one in 2007, but no pro- or antiimpact theory articles at all. Overall, dinosaur articles that concerned their extinction made up nearly $55 \%$ of the 66 articles in the "Research" section up to 1994. In 1990, strong evidence was produced that an undersea crater off the coast of Chicxulub in Mexico marked the site of an impact that occurred between Earth and an asteroid $\sim 10 \mathrm{~km}$ in diameter 65 m.y. ago (Hildebrand et al., 1991; Sigurdsson et al., 1991), and, at least as far as "Research" in Nature was concerned, the heat seems to have largely gone out of the debate, even though an "anti" article was published in 1993. We conclude that, for the "Research" section, this issue had been settled somewhat in favor of the "pros" by the mid-1990s. The dinosaur-related articles in the second half of our sample are far more concerned with characterizing these animals and their fellow creatures-feathers, flight, and the relationship to birds being one strong interest theme. The enormous numbers of new (Chinese, in particular) fossil specimens becoming available also boosted this aspect of paleontology.

The picture for the "News" section is somewhat different. Here, 69 articles appeared prior to the start of 1994, and
207 afterward. Of these, prior to 1994, nine were "pro," three were "anti," and 11 were "balanced," together making one third of the total. So "News" was proportionately less extinctionoriented in its discussion of the dinosaurs than "Research," although the total numbers of dinosaur articles (66 "Research," 69 "News") were very similar. After 1994, the proportion of "News" articles dealing with extinction issues is still relatively high: $20 \%$ of 207 , with the majority (22/41) "pro," as against just three "anti" and 16 "balanced." Given that the majority of extinction-orientated or extinction-mentioning "News" articles occur in the second half of our sample, and that they are far more "pro" than "anti," one might conclude that the issue, as far as Nature overall is concerned, is settled, and, insofar as the issue is newsworthy, the position of this leading scientific journal is pretty much "pro-impact." The picture, of course, is more complicated; in September 2003, Nature published an article that highlighted "squabbles" over access to core samples from the Chicxulub crater, which indicated that there were several in the scientific community who were far from convinced that the "dinosaur killer" had indeed been identified, either in particular or in general (Dalton, 2003). That said, if Clemens is correct in her assessment of the role of Nature (and Science) in informing the wider scientific community, one might deduce thatoutside of particular disciplinary niches-the impact theory was accepted as being correct throughout the 1990s, and as the leading explanation beyond then.

\section{NARRATIVES, NEWS VALUES, AND THE ROLE OF THE MASS MEDIA}

One of the most compelling mass media presentations of the demise of the dinosaurs is to be found in Walt Disney's Fantasia (1940). To the strains of Igor Stravinsky's Rite of Spring, colossal beasts tramp wearily across a sunbaked desert, scrapping over a wilted leaf or pool of not-quite-solid mud, crashing to the ground, carnivore next to herbivore, lesser on top of greater. In the end, there is nothing but a trail of footprints leading to the inevitable bone pile. The animation ends with floods and earthquakes, burying and re-exposing the dinosaurs' remains. Something has caused changes that make the dinosaurs lives impossible. That something is not explained, but their final trudge looks painful and prolonged; there is no coup de grâce. Had Disney's animators been aware of the impact theory, given their natural tendency to the dramatic and Stravinsky's stirring ballet, they would undoubtedly have used it. In contrast, the final cartoon in Anthea Turner's Blue Peter presentation (1994) has the dinosaurs being literally bowled over by the blast caused by the meteor impact. Nice and quick and "they never knew what hit 'em." Framing a story for the media-including the "News" section of journals such as Nature-has to follow certain conventions: For the print media, news values (Nelkin, 1987; Gregory and Miller, 1998) are key; for television, storytelling devices and rhetorics may be employed, as will be discussed later (Silverstone, 1987). 


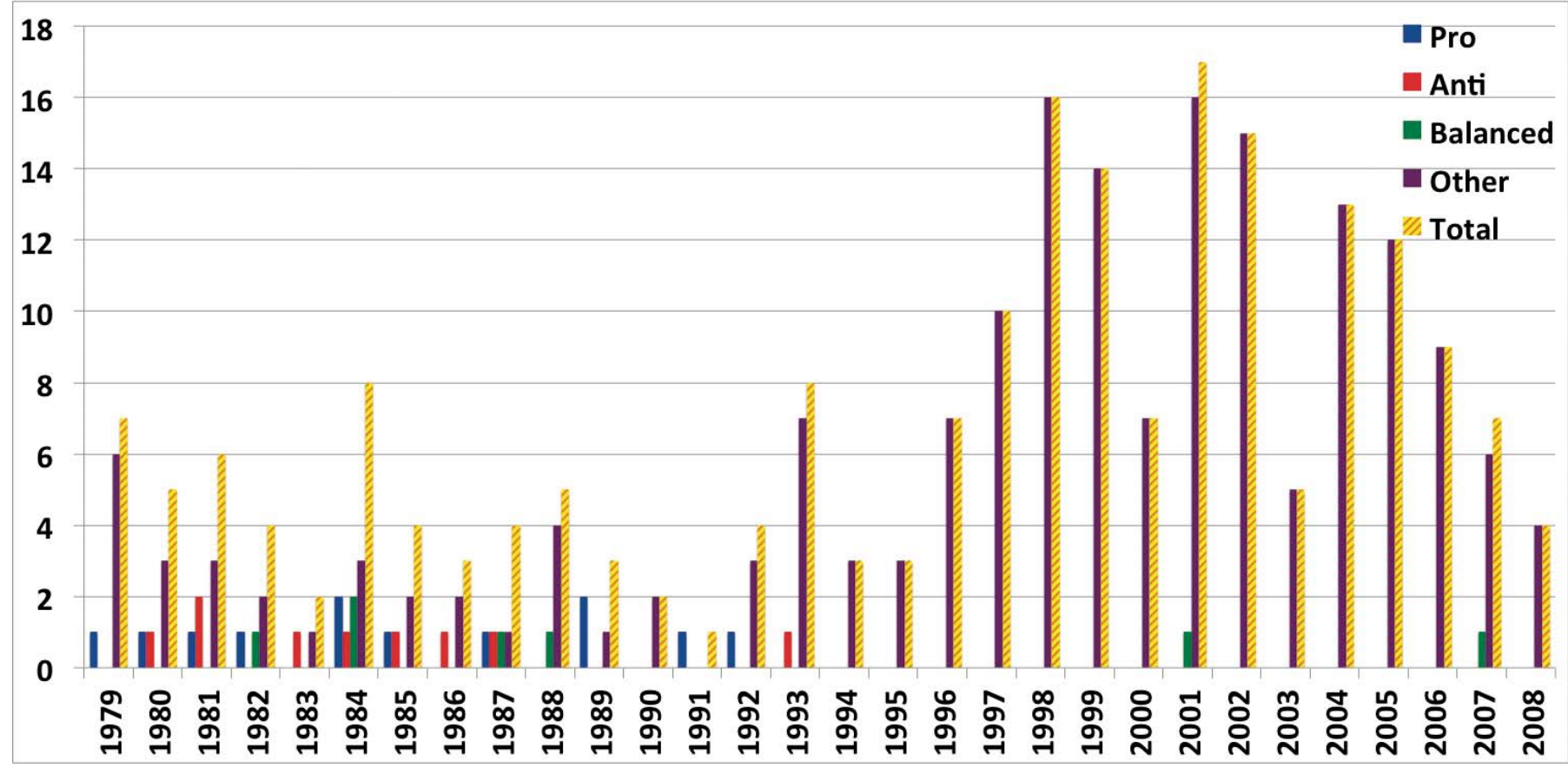

Figure 2. "Research" section coverage of the impact theory of the extinction of the dinosaurs by the leading general science journal Nature from 1979 to 2008.

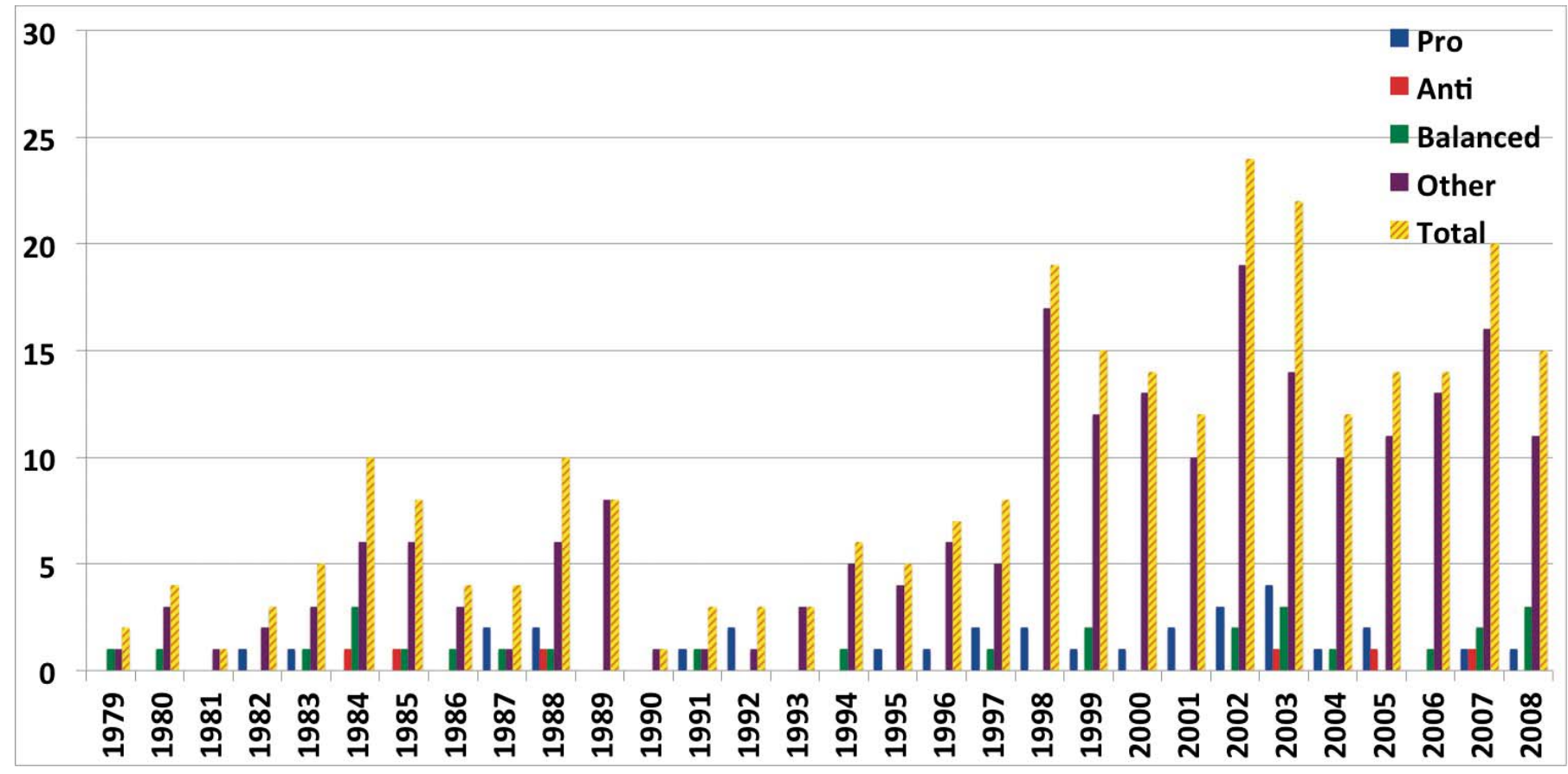

Figure 3. "News" section coverage of the impact theory of the extinction of the dinosaurs by the leading general science journal Nature from 1979 to 2008. 
Dorothy Nelkin's (1987, p. 111-112) groundbreaking study of science in the press emphasized the importance of "breaking news" and the urgency with which journalists had to work as factors that greatly influenced what could be covered, and in how much detail. Gregory and Miller (1998) built on the work of several media scholars to set out eight categories of news values. Table 1 lists these and picks out those that came into play in making Sullivan's (1980) article "newsworthy." Table 1 shows that the article hit many, if not all, of the key news value groups that journalists are looking for in a story. Most of these values continued to play a part in the popularization of research into the Cretaceous-Tertiary mass extinctions as time went on.

\section{SHOEMAKER-LEVY 9}

It was a comet with attitude and a problem. Captured by Jupiter sometime in the 1920 s, skimming too close to the surface of the giant planet in July 1992, Shoemaker-Levy 9 (SL9) was in fragments and on its final orbit when it was discovered by Carolyn and Gene Shoemaker and David Levy on 23 March 1993 (Shoemaker and Shoemaker, 1995). Once the orbital parameters of what Carolyn Shoemaker called the "squashed comet" were determined a few weeks after its discovery, it was clear that the 20-plus fragments would collide with Jupiter during the week of 16-23 July 1994, creating a series of multimegaton explosions (Marsden, 1995), although there was public and scientific controversy as to whether these would be real "bangs" or just "whimpers" (Radford, 1994; Weissman, 1994; Zahnle, 1995).

With a year to prepare, the international planetary science community was able to put together a major campaign to make use of every available telescope to watch Jupiter during that critical week (A'Hearn, 1995). Impact Week itself put to rest any doubts as to whether or not the collision would produce bangs or whimpers: There was the odd "whimper" as a fragment that was not very large or made of dust rather than rock-ice fizzled out, but for the most part it was "bangs" (Spencer, 1995). Jupiter was seen to be ringed with dark impact sites, some large enough to stretch from Washington to the mid-Atlantic, had they happened on Earth (Spencer, 1995; Chapman, 1995). The impacts had superheated and shocked the atmosphere of Jupiter for thousands of kilometers around the impact sites, creating chemical species new to the giant planet, throwing dust and debris high into the atmosphere, and even firing some of it off into space (Spencer, 1995; Dinelli et al., 1997). The immediate results filled much of the research section of one issue of Science (1995, v. 267), and there are now well over 1000 scientific papers that derive wholly or in part from the comet and its impacts, according to the National Aeronautics and Space Administration (NASA) Astrophysics Data System that logs them.

Prior to and during the run-up to the SL9 collisions, the scientific community was itself assessing the extent to which our own planet might be at risk from impacts. There were four key workshops between 1991, after the discovery of the Chicxulub crater, and 1993, just after SL9 had been discovered, that gave rise to a considerable volume of scientific work (Gehrels, 1994). In January 1994, Nature published a key review article by Clarke Chapman and David Morrison that estimated the annual likelihood of the average American being killed by a comet or asteroid impact to be somewhere between $1 / 3000$ and $1 / 250,000$, with a mean of $1 / 20,000$, making it comparable to dying in an airplane crash. They commented:

The impact hazard must be considered in parallel with, and balanced against, debates over society's priorities in dealing with other potential ecological disasters and hazards in general... Thus, by choosing whether or not to do something about this threat from the skies, society may establish a standard against which its responses to other hazards are measured. (Chapman and Morrison, 1994)

During 1993-1994, newspaper articles on SL9 ranged from features preparing for the impacts, such as the Independent's "By Jupiter, What a Bang" (Miller, 1993) and the New York Times' "Comet to Hit Jupiter with a Texas-Sized Bang" (Wilford, 1993). John Noble Wilford (1993, p. C1) told New Yorkers:

The astronomers are eagerly anticipating their first opportunity next July to observe explosive impacts on a planet that could be comparable in strength to the collision of a large asteroid or comet with Earth 65 million years ago, the catastrophe implicated in the mass extinctions of dinosaurs and many other species of life.

Assessing the likely scale of the impacts at somewhere between 1 and 100 million megatons of trinitrotoluene (TNT), Steve Miller (1993, p. 10) explained in the Independent:

To put the collisions in perspective, in 1908, our Earth ran into an asteroid. Exploding high above the ground, the mere 10 megatons of energy this collision produced were enough to flatten thousands of square kilometres of forest in the wilds of Siberia. At the other end of the scale, the comet that crashed into the Earth some 65 million years ago - and so changed our climate that the dinosaurs were wiped out-is reckoned to have produced a 100 million megaton detonation. Whatever the precise outcome, no one doubts that we will end up with a better understanding of the catastrophes which befall planets from time to time. How nice to be able to watch it happen on someone else's world. But comets are among the most unpredictable inhabitants of our solar system. One day it could be us.

As the comet fragments struck the giant planet (Fig. 4), all the major newspapers carried blow-by-blow reports. The Sydney Morning Herald told readers "Jupiter Under Bombardment" and had SL9 codiscoverer Eugene Shoemaker declaring: "For us it's Star Wars, only it's for real" (McCarthy, 1994, p. 1). A day later, Shoemaker was telling USA Today that "a fragment called G flared as bright as Jupiter itself on heat-measuring telescopes" (Hoversten, 1994, p. 3A), which he estimated to be equivalent to 6 million megatons of TNT for the Canadian Globe and Mail (Immen, 1994).

As far as the implications of the impacts were concerned for the safety of humanity from asteroid or cometary impacts (Fig. 


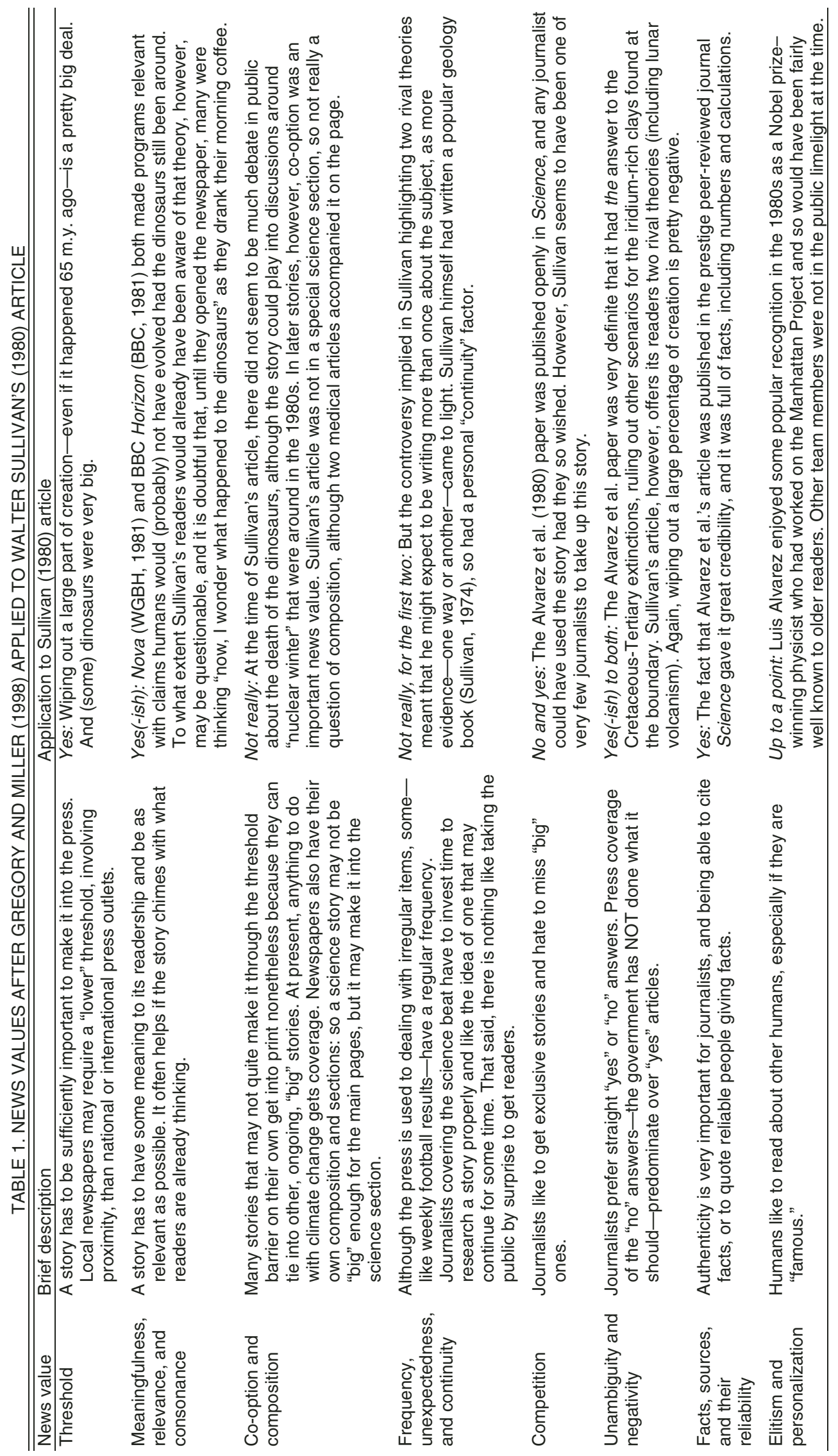




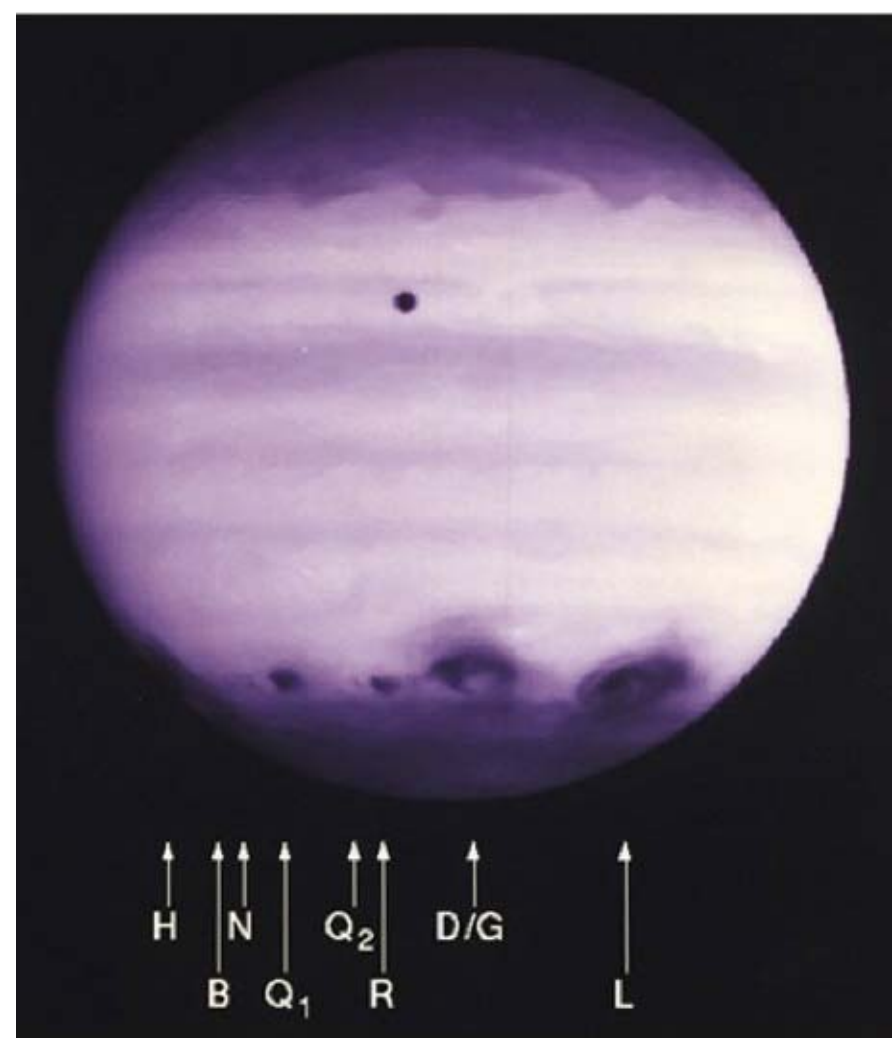

Figure 4. Hubble space telescope image of Jupiter immediately after Impact Week, with the impact sites denoted by letters. Credit: NASA.

5), Tim Radford (1994, p. 10) was typical of many: Writing in the Guardian's "Serial Killers from Heaven," he revealed:

Two scientists from Arizona and California this year calculated that there was a one in 10,000 chance of a $2 \mathrm{~km}$ diameter comet or asteroid colliding with the Earth in the next century, killing a very large section of humanity. A third calculated that the chances of death from an asteroid was about the same as death in an airline accident. This school of thought is called catastrophism. It argues that the planet, and with it the solar system, are not as they are because of the slow accretion of processes over time: they are also subject to periodic and catastrophic bumps.

In the middle of Impact Week, Nature opined:

The greater than expected impact of Comet Shoemaker-Levy 9 as it crashed into Jupiter this week is set to intensify the debate over what steps, if any, should be taken to deal with the prospects of such an object striking the Earth. (Macllwain and Verrell, 1994)

Nature noted that the proposal by the Spaceguard group, to build six $2.5 \mathrm{~m}$ telescopes dedicated to watching out for rogue asteroids or comets potentially on a collision course with our home planet, would receive a new impetus, although some leading scientists such as Carl Sagan were concerned about the use of nuclear weapons as part of a planetary defense strategy. So SL9

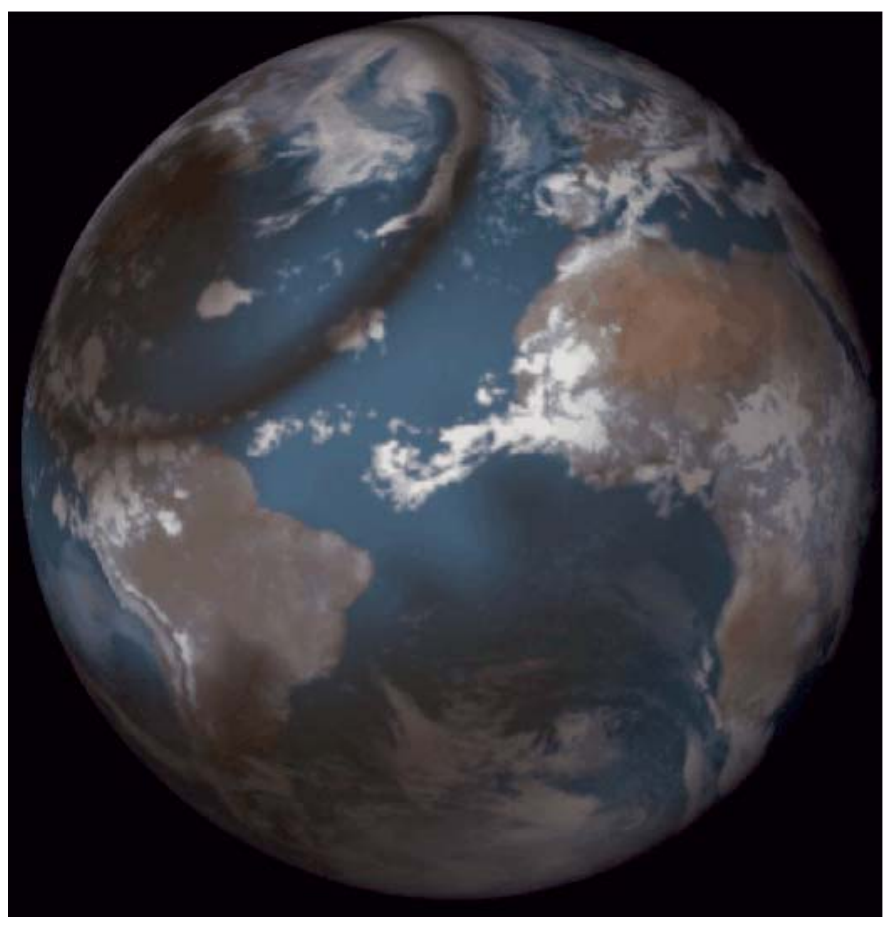

Figure 5. The impact site of Fragment $\mathrm{G}$ transposed onto an image of Earth and centered on Washington DC. Credit: NASA.

played into several preexisting scientific debates that had already been covered by several newspaper articles.

\section{LONG-TERM NEWSPAPER COVERAGE OF THE DEATH OF THE DINOSAURS}

While Clemens (1986) looked at a variety of popular publications, many of which clearly labeled themselves as "science" (e.g., Scientific American), another indicator of the popularization of theories concerned with the death of the dinosaurs can be obtained from looking at the general media. It has long been understood that, although newspapers may play a role in educating their readers, they operate under constraints that limit their ability to do so (for extensive and classic discussions of these issues, see Nelkin, 1987; Friedman et al., 1986). Privately owned newspapers are, fundamentally, commercial enterprises (witness the recent sale of the Washington Post). They may also be seen as cultural indicators, for our purposes giving an indication of the extent to which ideas from science have "diffused" into the wider citizenry, and can be referenced in such a way that all understand the allusion. So this article makes use of the Nexis database of "Major World Newspapers" (using the UK version of Nexis, to which the author has access) as a proxy for this popularization process, sampling newspapers for 30 years from the period 1 January 1979 to 31 December 2008. Thus, this general newspaper sample goes more than 20 years beyond Clemens' original (1986) work.

In this section, I set out to quantify the coverage of Alvarez' theory of the extinction of the dinosaurs, in terms of the 
number of articles published each year as a way of tracing both the "educational" and "cultural indicator" roles of general newspapers. In addition, I wish also to measure the extent to which the articles linked this "story" to events surrounding the planet Jupiter. Initially, therefore, two searches were carried out using the terms "dinosaur" and "impact/collision" and "term," where the final term was "asteroid/comet" (search 1), covering the key elements of the Alvarez impact theory, and "Jupiter" (search 2) in order, particularly, to uncover articles that linked the demise of the dinosaurs to the SL9 story.

For search 1, Nexis delivered 1770 returns. This sample was then refined by using only the 20 newspapers that returned 25 articles or more, so that each newspaper had the ability to generate a reasonable time series. The selected newspapers and the numbers of articles retrieved from Nexis for the two searches are shown in Table 2. Of the selected newspapers, five are from the United States, and six are from Australia (including one from Tasmania, the Hobart Mercury). Four have UK-wide coverage, and two more British papers are more restricted to Scotland. There are two Canadian papers, and the Irish Times is also included. So our sample is representative of the English-speaking world, but for some reason, the UK version of Nexis does not pick up major U.S. West Coast newspapers such as the Los Angeles Times or the San Francisco Chronicle. (These newspapers appear to have carried the first coverage of the Alvarez impact theory, in an article on 25 June 1979, reporting on Alvarez' discovery of the link between the iridium layer at Gubbio and the Cretaceous-Tertiary [K-T] boundary.)

Since we are interested in widespread public acceptance of the impact theory of the death of the dinosaurs, the selected articles are not limited to those that address this question directly. Some do, as in the case of Sullivan's (1980) original article reporting on the Alvarez et al. (1980) paper or the Australian Advertiser's "Victorian Fossil May Smash Theory on Dinosaurs'
Demise" (Australian Associated Press, 1986). However, others simply make reference to this issue as part of another topic that is their main focus, as in the case of the articles dealing with SL9 cited earlier or Dick Ahlstrom (1995) writing in the Irish Times, "Rare comet coming to the sky near you," alerting readers to the bright comet Hale Bopp. Articles in our sample ranged from short news items or announcements, some under 200 words, such as the Daily Mail's warning that asteroids heading toward Earth might be "indestructible" (Associated Press, 1998), or USA Today's report on efforts at Tel Aviv University to characterize asteroids (Weise, 2008). Others were well over 1000 words in length: in the New York Times, John Noble Wilford (1983) had nearly 2000 words to report in detail on the work of William Clemens at Hell Hollow, and how it contradicted the impact theory of the death of the dinosaurs; Stephen Mcginty (2002) used nearly 1800 words on page 2 of the Scotsman to try to persuade his fellow citizens that the danger of an impact ought to be of more importance to them than Mick Jagger's knighthood. Articles that had search terms completely unassociated with one another were manually rejected, but all others were retained, irrespective of their main topic, their position in the newspaper, or their overall length. Moreover, I placed no lower limit on the number of words or the percentage of the article that had to be devoted to the death of the dinosaurs: An article that simply contained a phrase such as "... wiped out the dinosaurs ..." in a story dealing with the threat to Earth from asteroid impacts (e.g., Mcginty, 2002) was taken as relevant, "culturally," if not "educationally," as well as implicitly endorsing the impact theory of their demise (see following).

Table 2 shows that the New York Times (USA) produced the most articles for both searches, followed by the Guardian (UK) for search 1, and The Times (UK) for search 2. The New York Times produced nearly eight times as many articles as the least productive newspaper in our sample-the Philadelphia Enquirer-for search 1, and over 14 times as many as the least

TABLE 2. NEWSPAPERS USED IN ANALYSIS OF THE MEDIA COVERAGE OF THE DEATH OF THE DINOSAURS

\begin{tabular}{|c|c|c|c|}
\hline Newspaper (Country) & Publication & Search 1 & Search 2 \\
\hline New York Times (USA) & Continuous & 198 & 43 \\
\hline Washington Post (USA) & Continuous & 127 & 26 \\
\hline The Times (including Sunday) (UK) & Continuous & 119 & 35 \\
\hline Globe and Mail (Canada) & Continuous & 88 & 16 \\
\hline Courier Mail (Australia) & Continuous & 73 & 24 \\
\hline Mail (UK) & Continuous & 57 & 13 \\
\hline Washington Times (USA) & From 1982 & 48 & 3 \\
\hline USA Today (USA) & From 1982 & 44 & 19 \\
\hline Advertiser (Australia) & Continuous & 44 & 8 \\
\hline Irish Times (Ireland) & Continuous & 42 & 13 \\
\hline Hobart Mercury (Tasmania) & Continuous & 40 & 11 \\
\hline Herald Sun (Australia) & From 1990 & 39 & 6 \\
\hline The Age (Australia) & Continuous & 38 & 11 \\
\hline
\end{tabular}


productive - the Washington Times-for search 2. The New York Times published at least one article on the demise of the dinosaurs every year from 1980 to 2008, with its coverage peaking in 1996 with 22 articles. In terms of consistency, the Washington Post (USA) missed just 2 years (1982 and 2008) in our sample, followed by the Globe and Mail of Canada, which returned in all but 1982, 1991, and 1999, and the Guardian, which returned articles starting in 1984, and from then on failed to publish an article only in 1987 and 1990. The consistency of the "elite" newspapers contrasted with the record of some of the more "down market" in our sample: USA Today published nothing prior to 1989, and then missed 1996 and 1999, and the Mail (UK) started in 1992, and missed 1995 and 1996.

Figure 6 shows the total number of articles published for our two searches (search 1, red; search 2, green), along with the articles that overlapped in the two searchers (purple). Allowing for this overlap, Figure 6 also shows the total numbers returned from Nexis for the total search on the term asteroid/comet/Jupiter. Of the 20 chosen newspapers, 16 have continuous publication throughout the 30 years from 1979, two commenced publication in 1982 (USA Today and Washington Times), the UK Independent began life in 1986, as a breakaway from The Times, and the Australian Herald Sun started in 1990. I have allowed for this by weighting the numbers of articles by 20 divided by the number of sample newspapers that were publishing. (In practice, this changes overall numbers by a maximum of two in any one year.)

It is possible to divide the period covered by the sample into three: 1979-1988, 1989-1998, and 1999-2008. In the first period, numbers of articles selected by search 1 rise fairly steadily to reach $20+$ per year by 1985 , and then level off. During this period, only eight of the selected newspapers (44\%) published search 1 articles, with only the New York Times publishing at least one article every year. During the next decade, article numbers increase steeply, with the percentage of newspapers having published at least one article rising from 58\% in 1989 to $100 \%$ by the end of 1994. As a result, total numbers increase by (nearly) a factor of 5 from 24 in 1989 to 119 in 1998. From 1999 to the end of the sample period, the general trend is for the number of articles to go down to the high forties in 2007 and 2008. As Table 3 shows, overall numbers of articles in each of the three decades went from 118 (1979-1988) to 658 (1989-1998) and then dropped slightly to 615 (1999-2008).

Several factors from within the relevant scientific disciplines can be linked to the considerable increase in articles published during the middle decade of the sample. (Note that I discuss some of the features within science communication and journalism later in this paper.) As noted already, 1991 marked publication of the detection of the Chicxulub crater (Hildebrand et al., 1991; Sigurdsson et al., 1991). In March of 1993, Comet ShoemakerLevy 9 was discovered on collision course for Jupiter the following July: Article numbers more than trebled from 25 in 1989 to 82 in 1994, and leaping from 40 in 1991 to 70 in 1992 and 1993.

Although individual years in the final decade never reached the high of nearly 120 in 1998, at an average of over 60 articles a year in the sample, it is clear that considerable interest in the demise of the dinosaurs, triggered by the events of the 1990s,

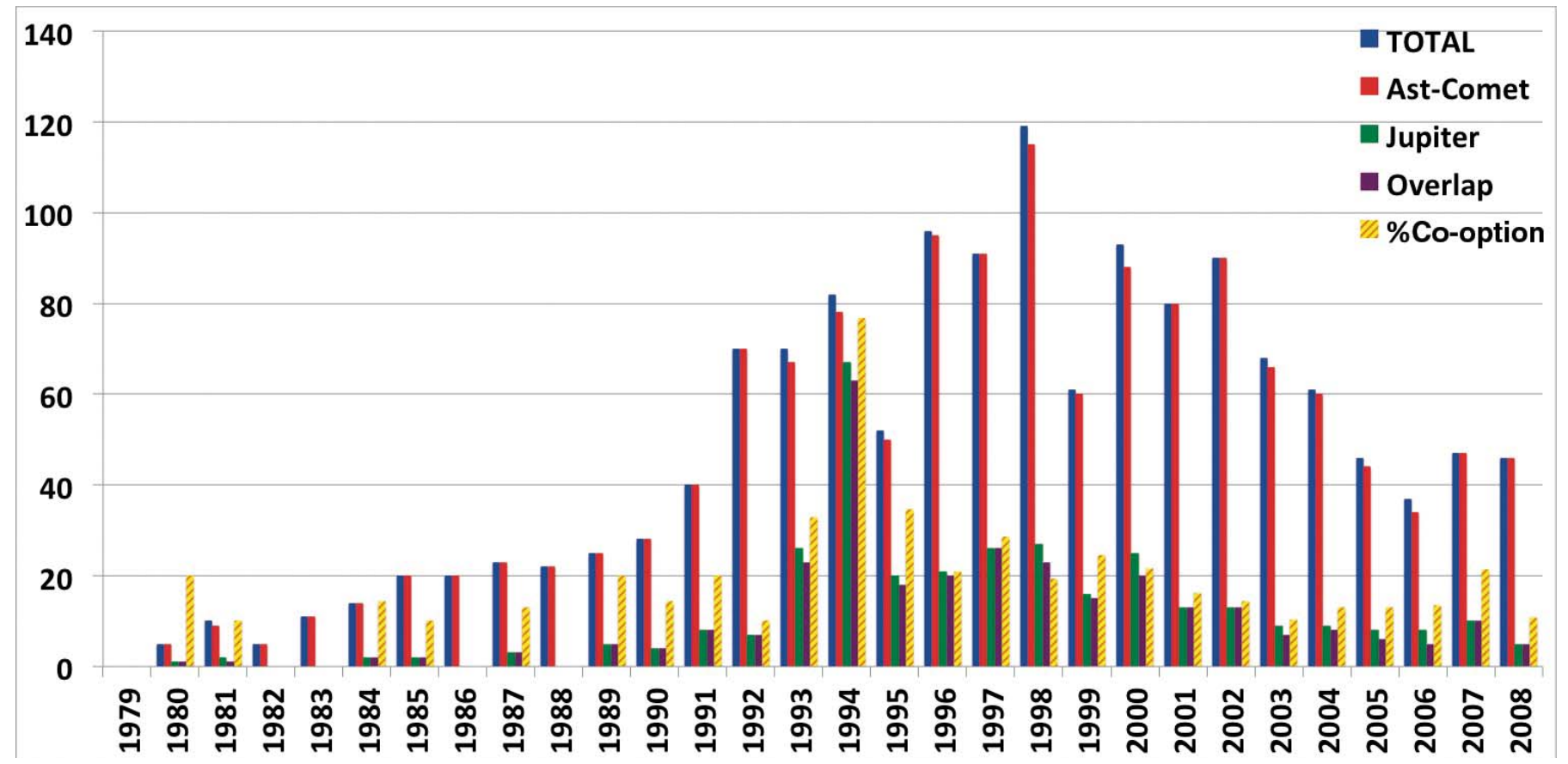

Figure 6. Numbers of newspaper articles in Nexis UK Major World Newspapers database from searches 1 and 2 (given in text). Numbers prior to 1982 are weighted by 1.25 , between 1982 and 1986 by 1.11 , and between 1986 and 1990 by 1.05 , to allow for the number of publishing newspapers in the sample. Also shown is the overlap between the two searches and the percentage cooption, $N_{\text {coop }}$, defined in the text. 
TABLE 3. NEWSPAPER COVERAGE BY DECADE AS SHOWN BY SEARCH 1

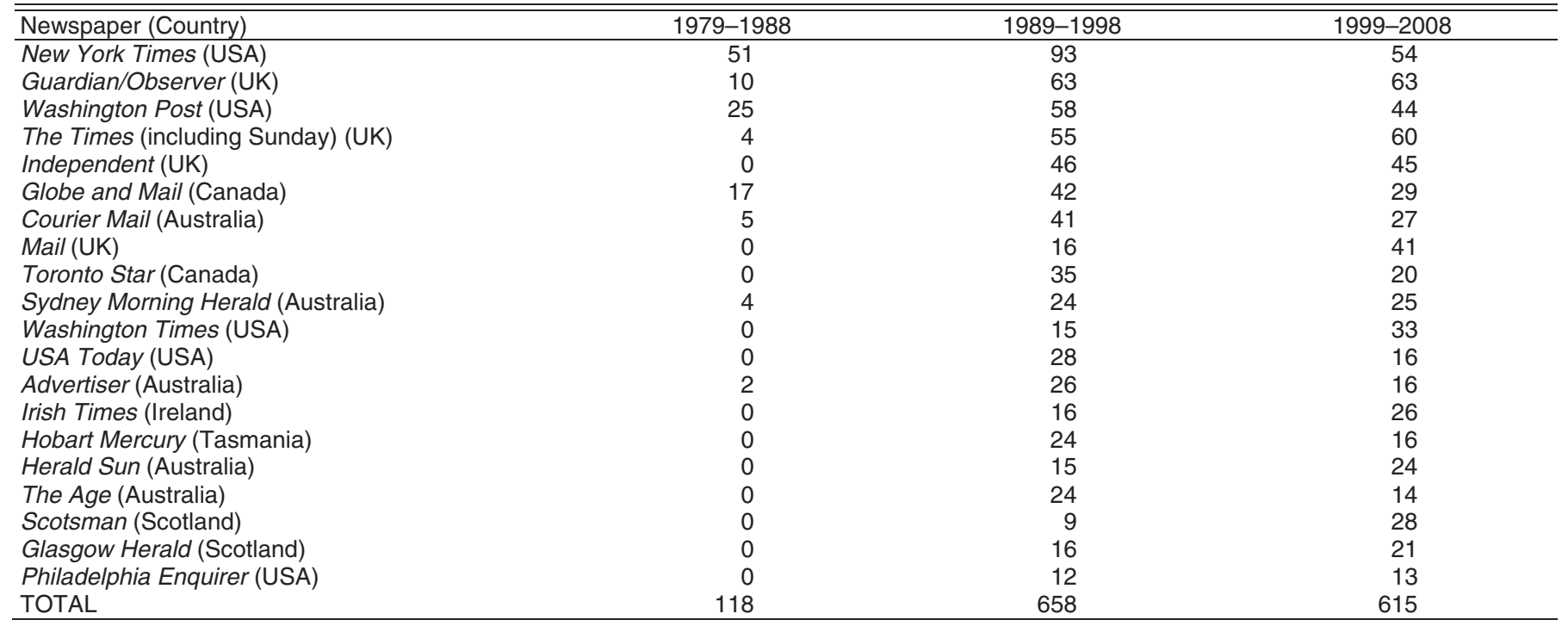

persisted. Within the sample, different newspapers showed varying behaviors. After the excitement of the middle decade, the New York Times settled back to its earlier coverage levels, but the UK's Daily Mail_-always on the lookout for something to worry about-increased its reports two-and-a-half-fold in 1999-2008.

\section{CO-OPTION AS A NEWS VALUE IN POPULARIZING THE DEATH OF THE DINOSAURS}

One of the news values listed in Table 1 is that of "co-option," a value that (usually) involves adding one story to another, longer-running, narrative to get over the required "threshold" for publication and create more public interest. In this article, I am investigating the link between the media interest generated by the impact of Comet SL9 on Jupiter in July 1994 and the process of popularizing the Alvarez theory. As well as the numbers of articles returned by searches 1 and 2, and the total number of individual articles the combined searches produced, Figure 6 also shows the overlap between the two searches (purple), and a "percentage co-option" (orange and yellow stripe), defined as:

$$
N_{\text {coop }}=[(\text { No. of Overlap Articles }) /(\text { Total No. of Articles })] \times 100,
$$

where the total number of articles is given by the sum of searches 1 and 2 less the number of Overlap Articles. For the first dozen years of our sample, $N_{\text {coop }}$ remains at $20 \%$ or below, dropping to just $10 \%$ in 1992, as the total number of articles exceeds 50 for the first time. However, it increases to $33 \%$ in 1993, as SL9 is discovered, and goes to $77 \%$ in 1994 , when it is clear that the majority of articles dealing with the death of the dinosaurs are linking the impacts on Jupiter with the impact(s) on Earth 65 m.y. previously; in 1995, where there is a postimpact lull in the total number of articles, $N_{\text {coop }}$ is around $35 \%$. Figure 6 shows that the percentage co-option remains at around $20 \%$ or above until the start of the new millennium, before falling back to around $10 \%$; with the general increase in coverage, however, the number of articles showing considerable overlap is always higher in the last decade of our sample than it was in the first. It would appear therefore that the co-option wrought in 1993-1995 around the time of the SL9-Jupiter collisions had an effect that lasted for at least 5 years, and probably longer.

Another way of thinking about co-option, however, is that a shorter-lived but highly newsworthy "event" may provide a "peg" on which to hang articles about a longer running story: the UK royal birth of Prince George (22 July 2013) gave newspapers an opportunity to run large numbers of articles giving the proud couple (and their readers) parenting advice, a topic many newspapers cover on a regular basis. To assess this effect, we modified search 1 so that the first term was "Jupiter" rather than "dinosaur" coupled with "impact/collision" and "asteroid/ comet" (search 3). The results are shown in Figure 7 on a yearby-year basis. The figure shows the numbers returned from search 3 across the sample of 20 newspapers, together with the overlap between those stories and those also containing the word "dinosaur." The figure shows that there was a very large peak in articles returned by search 3 in 1994, at the time of the SL9-Jupiter collision: 299 articles were found, i.e., four times as many as the next highest year, 73 in 1997. Once more, in Figure 7, I have shown the percentage co-option, $N_{\text {coop }}$. In this case, however, this is defined by:

$N_{\text {coop }}=[($ No. of Overlap Articles $) /($ No. of Search 3 Articles $)] \times 100$.

This results in some high values of $N_{\text {coop }}$ in the years leading up to 1992, when the total number of search 3 articles is low (only 


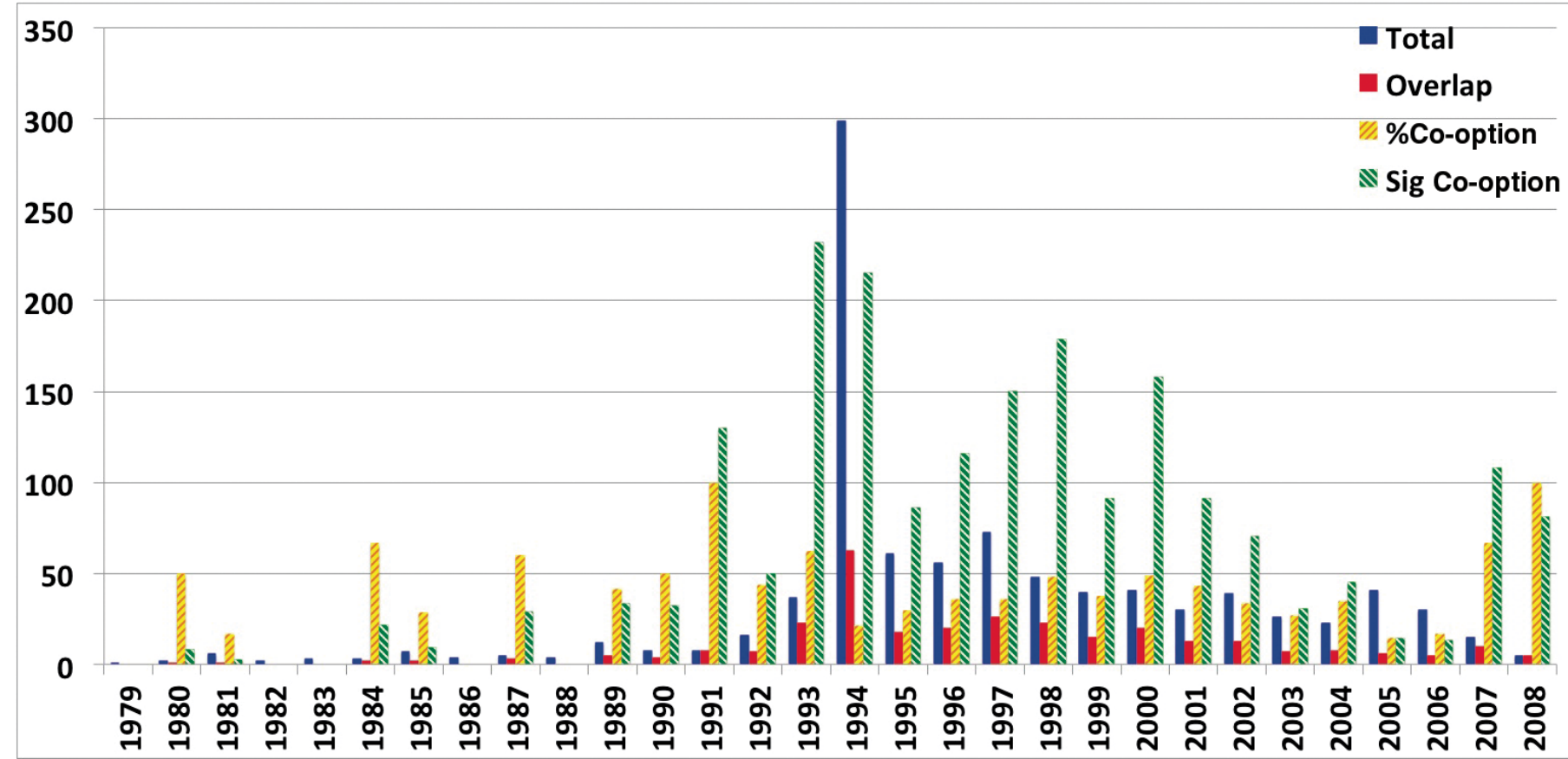

Figure 7. Numbers of newspaper articles in Nexis UK Major World Newspapers database from search 3 (given in text). Numbers prior to 1982 are weighted as Figure 8. Also shown is the overlap between the two searches and the percentage cooption, $N_{\text {coop }}$. The figure also shows "significant co-option," defined in the text. (Note that this has been scaled by 50 , so as to be easily seen on this figure.)

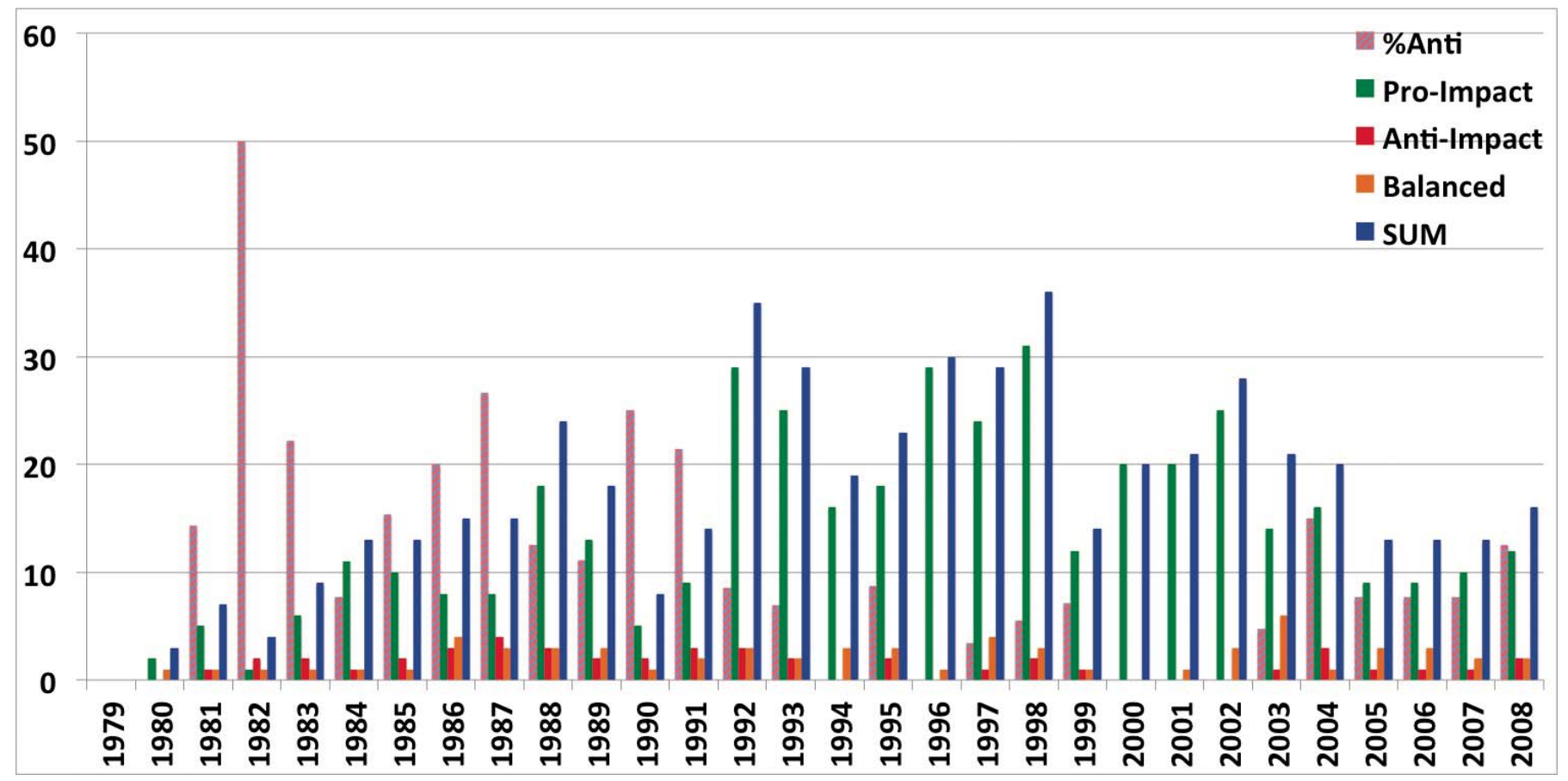

Figure 8. Coverage of impact theories of the demise of the dinosaurs in the New York Times (USA), the Washington Post (USA), the Guardian (UK) and the Globe and Mirror (Canada). For each year, the numbers giving coverage judged to be in favor of the impact theory (green), against (red), and balanced (orange) are shown, together with the percentage of articles against the impact theory (\%Anti, blue and red diagonal stripe, obtained by dividing the number of "anti" articles by the total number published that year [pro, anti, and balanced], expressed as a percentage). The total number (SUM, blue) for each year is also shown. 
after 1989 does it get above 10 in the sample), and relatively low values, when the overall numbers are large. However, the number of overlapping articles-i.e., those showing the co-option of the demise of the dinosaurs onto the stories about Jupiter and impacts (particularly that of SL9) — is highest in 1994, and I have attempted to illustrate the significance of this co-option by taking the number of overlapping articles into account, defining a "significant overlap" parameter:

$$
\begin{gathered}
\sigma_{\text {Coop }}= \\
{\left[N_{\text {Coop }} \times(\text { No. of Overlap Articles }) /\left(\Sigma_{\text {All_Years }} \text { No. of Overlap Articles }\right)\right],}
\end{gathered}
$$

where the denominator is the number of overlap articles in total, summed from 1979 to 2008 . Here, $\sigma_{\text {Coop }}$ peaks at over 4 in the SL9 years of 1993 and 1994, with a secondary peak of 3.5 in 1998 (the year of two Hollywood blockbusters discussed later). (Note that in Figure 7, $\sigma_{\text {Coop }}$ has been scaled by 50 to make it clearly visible on the plot.) Between them, Figures 6 and 7 show that whether the co-option is defined as enhancing the news value of the short-lived SL9 events through its link with the long-running demise of the dinosaurs or vice versa, there is a significant effect. Clearly, this is most significant in the SL9 years (1993 and 1994), but the effect can be seen continuing for the next decade.

\section{NEWSPAPER ATTITUDES TOWARD THE IMPACT THEORY}

To look more closely at the message that readers were getting about the demise of the dinosaurs, we have analyzed the articles in the New York Times (U.S.), the Washington Post (U.S.), the Guardian (UK), and the Globe and Mail (Canada), four newspapers that had the most consistent coverage of the demise of the dinosaurs from 1980 until 2008. In order not to miss articles that left out any reference to "impacts" or "collisions," the search was widened to include a search on the terms "dinosaur" and "death/demise/extinction/wiped out" plus "volcano/volcanism," since this is the main rival explanation to impacts as the cause of the Cretaceous-Tertiary mass extinction. The results of this additional search were added to those found in search 1, with any overlapping articles counted just once, producing a combined search, search 4. In this widened search, the New York Times had at least one article in each of the years covered, and the Washington Post now missed just 1982. The Globe and Mail missed 3 years (1982, 1991, and 1999), while the Guardian started its coverage in 1984 and then missed just 1987 and 1990, according to the sample. Overall, 523 articles resulted from these four newspapers covering all of the search items outlined earlier.

The results of search 4 are shown in Figure 8, where I have plotted the total number of articles in our four newspapers on a yearly basis (SUM, blue). Each article was read and analyzed to be put into one of three categories, "pro-impact" (green), "antiimpact" (red), and "balanced" (orange). Pro-impact articles argued for, reported positively on others' arguments, or mentioned the impact explanation for the death of the dinosaurs as if it were a matter of fact. Anti-impact articles argued for alternative explanations to the impact explanation, criticized it (with or without reporting evidence against impacts), or reported others' criticisms of it. Balanced articles reported impact theories alongside alternative explanations, reported on impact theories while indicating that there were considerable doubts, or simply left unanswered what was the cause of the demise of the dinosaurs. Figure 8 shows the numbers of the articles by category on a yearly basis.

In all years, "pro" articles outnumbered "anti" articles, with the exception of 1982, which had the second lowest number of articles in the search 3 sample (4; lowest is 1980 with 3). Over the whole period from 1980 to 2008, I categorized 415 articles as pro-impact, 45 as anti-impact, and 63 as balanced. The year 1998 saw the highest number of articles in the sample, 36, with the highest number of "pro" articles, 31. The highest number of "anti" articles was published in 1987, with 4 out of 15 against the impact theory (still outnumbered by 8 in favor). To allow for the differing numbers of articles in each year, Figure 8 also gives the percentage of those articles (\%Anti, blue and red diagonal stripe in Fig. 8) that were characterized as "anti." This is obtained by dividing the number of "anti" articles by the total number published that year (pro, anti, and balanced), expressed as a percentage. The years with the highest percentages of "anti" articles were 1982 (50\%, 2 out of 4) and 1987 $(27 \%, 4$ out of 15$)$. The average percentage of "anti" articles is $8.6 \%$ over the three decades.

Figure 8 shows that the time period can be split into two halves, centered on 1994, the first year after the original 1980 Alvarez et al. paper when no articles against the impact theory were published in any of the four newspapers. Up to 1993, the sample generated 207 articles, and after 1994, it generated 297, with 19 occurring in 1994 itself. In the 14 years from 1980 to 1993 , only the first year has no "anti" articles; in the 14 years following 1994, there are four such years. (As pointed out already, 1994-the year of the SL9-Jupiter impacts - also had no "anti" articles.) In the first 14 years, half have percentage "anti" articles greater than the overall average of $8.6 \%$, although numbers decline in 1992 (8.6\%) and $1993(6.9 \%)$ from higher values in the two preceding years ( $25 \%$ and $21 \%$, respectively). In the second 14 years, there are just three years, 1995 (8.7\%), 2004 (15\%, the year that Keller et al. [2004a, 2004b] published evidence that the Chicxulub impact predated the Cretaceous-Tertiary mass extinction), and 2008 (12.5\%, the year that Keller et al. [2008] published evidence linking the Cretaceous-Tertiary mass extinctions with Deccan Traps volcanism), when this happens. Consequently, the pre-1994 average of "anti" articles is $17.3 \%$ - twice the overall average-compared with just $5.7 \%$ afterward. After 1994, post-SL9, the landscape for journalism about the demise of the dinosaurs had clearly changed strongly in favor of the impact explanation. 


\section{CHANGING NEWSPAPER ENVIRONMENT FOR SCIENCE}

Alongside the numbers of newspaper articles and their characterization outlined herein, it is also important to take account of changes in the newspaper environment for science that may affect levels and styles of reporting. The period from the mid1980s to the mid-1990s saw the numbers of newspapers with science sections and the numbers of journalists on the "science beat" grow, although not evenly across the English-speaking world: in the U.S., 95 newspapers had their own science section by 1989 (Brumfiel, 2009), while in the UK, the number of science journalists doubled from this date to reach over 80 by 2005 (Williams and Clifford, 2009). This coincided with greater efforts to increase "scientific literacy" (U.S.) and "public understanding of science" (UK): The American Association for the Advancement of Science of published its "Project 2061: Benchmarks for Scientific Literacy" in 1993 (AAAS, 1993) following an intense 4-year long effort to work out what the average American should know about science by the time Comet Halley next returned (in 2061); in the UK, the Royal Society's "Report on the Public Understanding of Science" (Bodmer, 1985) had, amongst other things, recommended an increase in the amount of science that British newspapers should carry, and that scientists should "consider it their duty" to tell their fellow citizens what they were doing.

By the middle of the 2000s, however, commercial pressures and those from "new media" had led to a sharp decline in science sections in U.S. newspapers to 34 in 2004 (Brumfiel, 2009), while Williams and Clifford (2009) noted that the numbers of UK science journalists have remained static since around that time, with some downward pressure. Looking at Figure 6 and Table 3 , one can see evidence for these trends at work in the case of the demise of the dinosaurs, although individual newspaperssuch as the Washington Times (USA), the Daily Mail (UK), the Herald Sun (Australia), and the three newspapers from the Celtic fringe - go against this trend, at least until 2008.

It is far more difficult to explain away the change in attitude toward the impact explanation for the death of the dinosaurs (Fig. 8) solely by a changing media environment, unless one is going to argue that along with an expansion in science coverage, there was dumbing down to the extent that only one explanation was "allowed." The figures shown herein give little evidence for this, however: While the number of "anti" articles halved from 30 to 15 in the post-1994 period, the number of "balanced" articles increased from 27 to 36 in the four, somewhat "elite," newspapers I used in this part of the study, all of which have good coverage prior to and subsequent to 1994 .

\section{DOCUMENTARIES AND FILMS}

The fact that the story sparked by Alvarez et al.'s paper was newsworthy and noteworthy was sine qua non for it to be turned into a television documentary or a film. Television as a medium is much more demanding in terms of time and effort than print; to justify such investment thus requires any story to be a proportionately "bigger deal." The first television depiction of the impact theory came quite soon after the Alvarez et al. (1980) paper was published: In 1981, the WGBH channel put out a documentary in its Nova series called "The Asteroid and the Dinosaur" (WGBH, 1981). Its publicity material announced: "For 150 million years, dinosaurs dominated the Earth. Then, 65 million years ago, they suddenly vanished, along with a great deal of the planet's animal and plant life. NOVA examines a remarkable theory about the cause of the catastrophe - in which the first clue to the solution was a piece of clay." Later that year, the BBC's flagship science documentary program Horizon broadcast The Death of the Dinosaurs, a 50-min-long program, much of it shot on location and making use of the latest graphics and modeling, in which the Alvarez team featured heavily, although not, ultimately, as the heroes of the hour (BBC, 1981). That honor went to Italian paleontologist Cesare Emiliani, who explained the "kill mechanism" in now-familiar impact-provokes-devastating-climate-change terms.

This program formed the basis of a detailed examination of television science by media researcher Roger Silverstone (1987). His analysis of television science in general centers on the use of "narrative strategies" and their accompanying "rhetorics." The "mythic strategy" is very much about telling stories about heroes and villains, facing challenges and trials, and their eventual triumph. In this case, "detectives" Alvarez, Alvarez, Asaro, and Michel face the mystery of the missing dinosaurs, with only the "smoking gun" of iridium-rich clays to mark where they came to grief. Undaunted, they use their forensic skills to solve the puzzle. However, from an initial high, the story turns downward into despair as every attempt to find the clinching evidence fails. Enter the new hero, Emiliani, who comes up with the solution, winning the day for science-kind against the alien invader.

Silverstone's "mimetic strategy" plots the way-using rhetorics of image, lighting and framing, and voice-to mimic the scientific process and the way scientists actually work. So the puzzle is set: Why and how did the dinosaurs die out, and what difference would it have made if they did not? Scientists are seen in the field, the office, and the analysis laboratory, and the evidence is analyzed and conclusions reached. However, Silverstone (1987, p. 314) warns:

The narrative of a television programme, even of a documentary programme, has no necessary relationship to the world to which it refers ... The narrative is constructed on the basis of conventions and rules which are generally applicable, recognisable and effective...Television's texts are therefore not true but plausible (my emphasis).

Television's products can thus only give an indication of how the science is done and to what effect; the product seen is always a "dramatization." Nonetheless, the applicability of television to the debate around the death of the dinosaurs means it is a subject to which broadcasters have returned on many occasions.

During the 2000s, surveys have shown that adults get much of their general information and knowledge about science from 
the broadcast media (e.g., Commission of the European Communities, 2005), although the internet was fast increasing as a source of information about specific items (particularly health information). This article focuses on general newspapers as sources of information and as cultural indicators, and a detailed analysis of the way in which television, radio, and film industries have dealt with issues surrounding the demise of the dinosaurs is outside of its scope. However, a few comments are in order.

In the run-up to the SL9 impacts, during, and after them, television and radio news programs around the world broadcast items about the science of the event, the biter and the bit, many of which made at least passing reference to impact causes for the Cretaceous-Tertiary mass extinctions. These are so many and-by their nature - so ephemeral, and often embedded in newsroom conversations rather than actual items, as to be impossible to quantify and analyze. However, television documentaries do give a picture of changing media — and by implication, public — perceptions.

Prior to the impact of SL9 with Jupiter, only the 1981 Nova (WGBH, 1981) and Horizon (BBC, 1981) documentaries had dealt with the death of the dinosaurs, both of them publicizing the work of Alvarez et al. (1980), although not uncritically. After a decade during which the program-makers ignored the subject, SL9 brought on a flourish of impact-related documentarieseight in the following decade - all of which made mention of the death of the dinosaurs, if not the Alvarez team explicitly. The majority of these-explicitly or implicitly_endorsed the impact theory, particularly if the program centered on threats to Earth (e.g., "Hunt for the Doomsday Asteroid," BBC, 1994). Additionally, in 1998, Hollywood released two blockbusters-Deep Impact and Armageddon - both of which had a comet en route to hit Earth as their central plotline. Scripted into those films were allusions to the Cretaceous-Tertiary extinctions, pretty much uncritically supporting impacts as the killer blow.

So what of alternative explanations? In 2000, the BBC's Horizon series had screened "Supervolcanoes" (BBC, 2000), which centered on the mass killing of rhinoceroses in Nebraska some 10 m.y. ago as the result of a supervolcanic eruption $1600 \mathrm{~km}$ away, but this did not mention the Cretaceous-Tertiary extinctions, despite 25 years of scientific papers that linked the Deccan Traps eruptions with them (McLean, 1985; Courtillot et al., 1986). Not until 2004, 10 years after SL9, when "What Really Killed the Dinosaurs?" (BBC, 2004) was broadcast, did a major counter-theory to the original Alvarez et al. (1980) asteroid impact explanation get significant air time. In that, U.S. researcher Gerta Keller was able to demonstrate some of the inconsistencies of the single impact killer theory, ideas she had been championing for well over a decade (e.g., Ward et al., 1995). That said, in "Asteroids - the Good, the Bad, and the Ugly," Horizon once more cast impacts by these bodies as the killers responsible for the Cretaceous-Tertiary extinctions (BBC, 2010). In the broadcast media, even more so than in print, impacts really do have impact.

\section{CONCLUSIONS}

A fringe often builds up around major news events. SL9, once it became publicly well known, gave rise to several. One self-styled "astronomer and plain-clothes nun," who called herself Sister Marie Gabriel, decided that what was going to happen to Jupiter was a wake-up call to the world, its religious and secular leadership in particular (Gabriel, 1994). After the impacts, pigeon racers (known as fanciers) across the UK blamed the loss of their favorite birds to what was happening to Jupiter (Wainwright, 1994), and the cartoon world had a field day. A tongue-incheek analysis of the reason for the extensive media coverage of SL9 came in the form of a Guardian cartoon (see Fig. 9), according to which journalists were left with nothing to fill their pages during the summer months when various legislative bodies were in recess, and the soccer World Cup had finished.

As noted at the time in Nature (MacIlwain and Verrell, 1994), SL9 also played into the policy discussions around planet

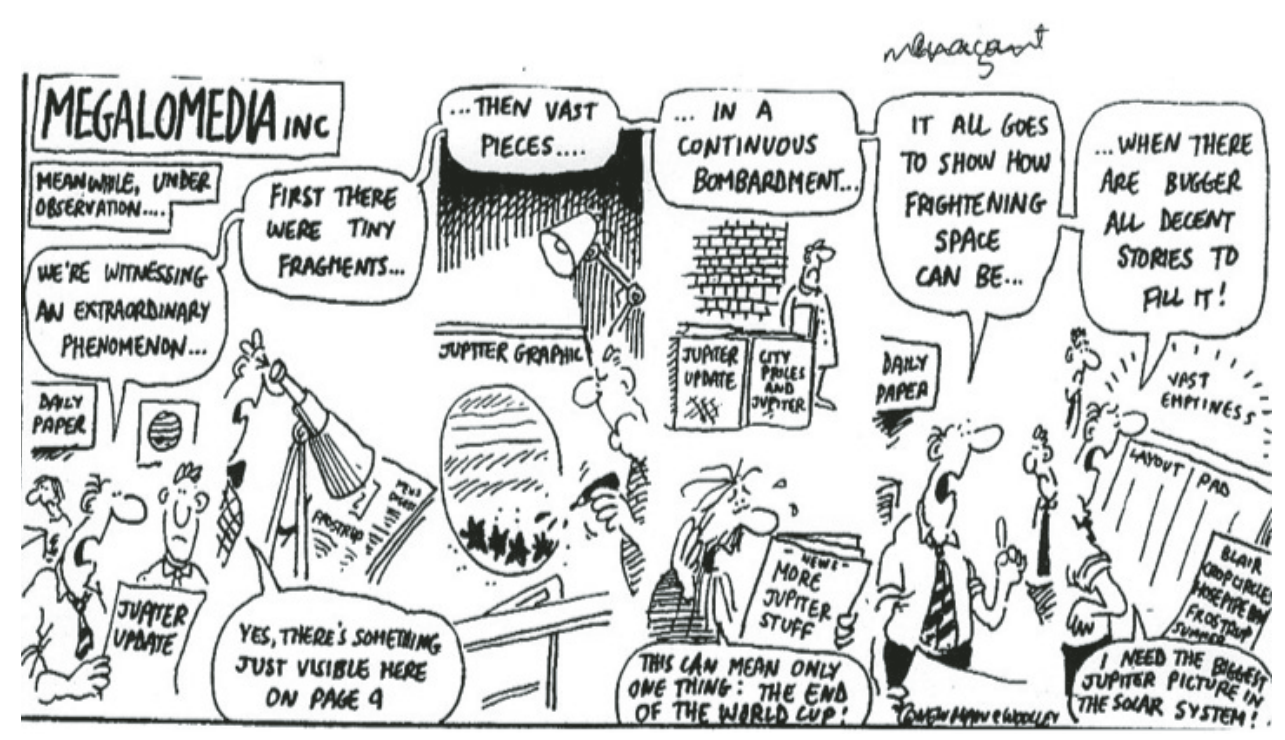

Figure 9. Cartoon in the Guardian newspaper explaining the reason for the extensive coverage of the collision of Comet Shoemaker-Levy 9 (SL9) with Jupiter. Reproduced by kind permission of Nick Newman and Ben Woolley. 
protection from impact hazards, with the dinosaurs being cited as the way not to go. Some of this discussion may have been stimulated by astronomers keen to boost their own funding, if the work of Mellor (2010) is correct. That said, post-SL9 policy documents have taken on board the potential threats, and NASA and the European Space Agency have a joint program to track and-potentially - deflect or destroy potential impactors (e.g., Atkinson et al., 2000; European Space Agency Web site, 2014).

For the "general public" - and that includes many in the scientific community who are not intimately involved in debates around the numerous mass extinctions that have occurred during the history of life on Earth, as well as politicians - understandings about what was responsible for the major extinctions at the time of the Cretaceous-Tertiary boundary (whenever that is exactly dated) are formed by the sources of information available to them. In the wider scientific community, journals such as Nature and Science can be hugely influential in the case of crossdisciplinary debates (Clemens 1986, 1994), as well as the more mass-circulation media (Lewenstein, 1995).

Looking at the "Research" section of Nature, we conclude that the Alvarez et al. (1980) impact theory had been very much settled by the early 1990s, after the discovery of the Chicxulub crater and its accompanying tektites (Hildebrand et al., 1991; Sigurdsson et al., 1991; Smit, 1991). The general newspaper coverage examined in this article gives a somewhat different picture, however (as does the "News" section of Nature). Although it is clear that the impact theory was gaining public ground in the early 1990s as scientists found their "smoking gun" (Hildebrand et al., 1991; Sigurdsson et al., 1991; Smit, 1991), the watershed year in terms of the numbers of articles in the general newspapers in favor and against seems to be 1994, the year of SL9: In that year, for the first time since Alvarez et al. (1980) published their Science paper, there are no articles against the impact theory in the New York Times, the Washington Post, the Guardian, or the Globe and Mail, and the degree of cooption-SL9 onto the death of the dinosaurs and vice versa-measured across all 25 newspapers studied pivots on this year. The impact theory thus received considerable exposure throughout the general public as it was carried along with the mass media coverage of the impacts of Comet SL9 with Jupiter, and it is clear that this explanation for the death of the dinosaurs remains the main "public perception," insofar as nonspecialist citizens have a view on the matter and those views are reflected in the mass media, even if the SL9 effect has now faded.

\section{ACKNOWLEDGMENTS}

I would like to acknowledge the work of several students during the University College London course "Popularisation of the Physical Sciences," run either as HPSC C317 or HPSC 3010, by the Department of Science and Technology Studies, which augmented my own researches. In particular, thanks go to Anna Lewcock, Stephanie McGovern, and Becky Whitham, for their work on analyzing press coverage of the death of the dinosaurs and SL9, which prompted my own, wider, searches, to Nimish
Lad and Nathaniel Hass, for work on the coverage by Nature and Science, which again I have extended, and to Hunain Dosani, Lucy Harmer, and Alison Somerville, for work on television documentaries. Linda Mao pointed out to me the role of Boss Tweed in disrupting the building of dinosaur statues in Central Park.

\section{REFERENCES CITED}

A'Hearn, M.F., 1995, The international observing campaign, in Spencer, J.R., and Mitton, J., eds., The Great Comet Crash: The Collision of Comet ShoemakerLevy 9 and Jupiter: Cambridge, UK, University Press, p. 39-44.

Ahlstrom, D., 1995, Rare comet coming to the sky near you: Irish Times, 18 March 1995, p. 3.

Alvarez, L.W., Alvarez, W., Asaro, F., and Michel, H.V., 1980, Extraterrestrial cause for the Cretaceous-Tertiary extinction: Science, v. 208, p. 10951108, doi:10.1126/science.208.4448.1095.

American Association for the Advancement of Science, 1993, Benchmarks for Science Literacy: Oxford, UK, Oxford University Press, 448 p.

Associated Press, 1998, The Indestructible Asteroids: Daily Mail, 4 June 1998, p. 28.

Atkinson, H., Tickell, C., and Williams, D.A., 2000, Report of the Task Force on Potentially Hazardous Near Earth Objects: London, Her Majesty's Stationary Office, $59 \mathrm{p}$.

Australian Associated Press, 1986, Victorian fossil may smash theory on dinosaurs' demise: The Advertiser, 28 April 1986, p. 7.

BBC, 1994, Hunt for the Doomsday Asteroid: Horizon, v. 30.2, February 28.

Bodmer, W., Chair, 1985, The Public Understanding of Science: Report of a Royal Society ad hoc Group endorsed by the Council of the Royal Society: London, The Royal Society, 46 p.

Bramwell, V., and Peck, R.M., 2008, All in the Bones: A Biography of Benjamin Waterhouse Hawkins: Philadelphia, Pennsylvania, Academy of Natural Sciences, $128 \mathrm{p}$.

British Broadcasting Corporation (BBC), 1981, Death of the dinosaurs: Horizon, v. 18.8, 16 November 1981.

British Broadcasting Corporation (BBC), 2000, Supervolcanos: Horizon, v. 36.8, 3 February 2000.

British Broadcasting Corporation (BBC), 2004, What really killed the dinosaurs: Horizon, v. 41.4, 7 October 2004.

British Broadcasting Corporation (BBC), 2010, Asteroids-The good, the bad and the ugly: Horizon, v. 47.6, 3 November 2010.

Broks, P., 2006, Understanding Popular Science: Maidenhead, UK, Open University Press, $200 \mathrm{p}$

Brumfiel, G., 2009, Supplanting the old media: Nature, v. 458, p. 274-277, doi:10.1038/458274a.

Burchell, J.D., 1975, Lord Kelvin and the Age of the Earth: London, Macmillan Press, $278 \mathrm{p}$

Chapman, C.R., 1995, What if...?, in Spencer, J.R., and Mitton, J., eds., The Great Comet Crash: The Collision of Comet Shoemaker-Levy 9 and Jupiter: Cambridge, UK, Cambridge University Press, p. 103-108.

Chapman, C.R., and Morrison, D., 1994, Impacts on the Earth by asteroids and comets: Assessing the hazard: Nature, v. 367, p. 33-40, doi:10.1038/367033a0.

Clemens, E.S., 1986, Of asteroids and dinosaurs: The role of the press in the shaping of scientific debate: Social Studies of Science, v. 16, p. 421-456, doi: $10.1177 / 030631286016003002$.

Clemens, E.S., 1994, The impact hypothesis and popular science, in Glenn, W., ed., The Mass Extinction Debates: How Science Works in a Crisis: Stanford, California, Stanford University Press, p. 92-120.

Close, F., 1990, Too Hot to Handle: The Race for Cold Fusion: London, W.H. Allen, $167 \mathrm{p}$.

Commission of the European Communities, 2005, Eurobarometer 2005: Brussels, Commission of the European Communities, 336 p.

Courtillot, V., Besse, J., Vandamme, D., Montigny, R., Jaeger, J.-J., and Capetta, H., 1986, Deccan flood basalts at the Cretaceous/Tertiary boundary? Earth and Planetary Science Letters, v. 80, p. 361-374, doi:10.1016/0012 $-821 X(86) 90118-4$.

Dalton, R., 2003, Hot tempers, hard core: Nature, v. 425, p. 13-14, doi:10.1038/425013a.

Darwin, C.R., and Costa, J.T., 1859/2009, The Annotated Origin: A Facsimile of the First Edition of On the Origin of Species: Cambridge, Massachusetts, Harvard College, 286 p. 
Davy, H., 1805/1980, Humphry Davy on Geology: The 1805 Lectures for the General Audience: Madison, Wisconsin, University of Wisconsin Press Ltd., p. 57-70.

Dinelli, B.M., Miller, S., Achilleos, N., Lam, H.A., Cahilll, M., Tennyson, J., Jagod, M.-F., Oka, T., Helico, J.-C., and Geballe, T.R., 1997, UKIRT observations of the impact and consequences of Comet Shoemaker-Levy 9 on Jupiter: Icarus, v. 126, p. 107-125, doi:10.1006/icar.1996.5630.

Fantasia, 1940, Disney, W., director, Burbank, California, Walt Disney Studios. European Space Agency, Near-Earth Objects-NEO Segment, http://www .esa.int/Our_Activities/Operations/Space_Situational_Awareness/Near -Earth_Objects_-_NEO_Segment (accessed 25 October 2013).

European Space Agency, 2014, http://www.esa.int/ESA (accessed 25 October 2013).

Friedman, S.M., Dunwoody, S., and Rogers, C.L., eds., 1986, Scientists and Journalists: Reporting Science as News: New York, The Free Press, Macmillan, Inc., $333 \mathrm{p}$.

Fyfe, A., and Lightman, B.V., 2007, Science in the Marketplace: Chicago, Illinois, University of Chicago Press, 432 p.

Gabriel, Sister M., 1994, World news flash: An SOS! to all world leaders: Various UK newspapers, paid advertisement during February 1994.

Gehrels, T., ed., 1994, Hazards due to Comets and Asteroids: Tucson, Arizona, University of Arizona Press, $1300 \mathrm{p}$.

Glasstone, S., 1983, The Effects of Nuclear Weapons: Washington, D.C., Government Printing Office, $69 \mathrm{p}$.

Gomes, R., Levison, H.F., Tsiganis, K., and Morbidelli, A., 2005, Origin of the cataclysmic Late Heavy Bombardment period of the terrestrial planets: Nature, v. 435, p. 466-469, doi:10.1038/nature03676.

Gregory, J., 2003, The popularisation and excommunication of Fred Hoyle's "life from space" theory: Public Understanding of Science (Bristol, England), v. 12, p. 25-46, doi:10.1177/0963662503012001245.

Gregory, J., and Miller, S., 1998, Science in Public: Communication, Culture and Credibility: New York, Plenum, p. 110-114.

Hildebrand, A.R., Penfield, G.T., Kring, D.A., Pilkington, M., Camargo, A.Z., Jacobsen, S.B., and Boynton, W.V., 1991, Chicxulub crater: A possible Cretaceous/Tertiary boundary impact crater on the Yucatán Peninsula, Mexico: Geology, v. 19, p. 867-871, doi:10.1130/0091-7613 (1991) 019<0867:CCAPCT>2.3.CO;2.

Hilgartner, S., 1990, The dominant view of popularization: Conceptual problems, political uses: Social Studies of Science, v. 20, p. 519-539, doi:10.1177/030631290020003006.

Hoversten, P., 1994, Jupiter hit with a 'big wallop’: USA Today, 19 July 1994, p. 3A.

Immen, W., 1994, Comet collision blinds scopes: The Globe and Mail, 19 July 1994, p. 1.

International Astronomical Union, 1993, Comet Shoemaker-Levy (1993e): Central Bureau for Astronomical Telegrams Circular 5725, March, $26 \mathrm{p}$.

Keller, G., Adatte, T., Stinnesbeck, W., Rebolledo-Vieyra, M., Urrutia Fucugauchi, J., Kramar, U., and Stueben, D., 2004a, Chicxulub crater predates K-T boundary mass extinction: Proceedings of the National Academy of Sciences of the United States of America, v. 101, no. 11, p. 3753-3758, doi:10.1073/pnas.0400396101.

Keller, G., Adatte, T., and Stinnesbeck, W., 2004b, More evidence that Chicxulub predates KT boundary: Meteoritics \& Planetary Science, v. 39, p. 1127-1144, doi:10.1111/j.1945-5100.2004.tb01133.x.

Keller, G., Adatte, T., Gardin, S., Bartolini, A., and Bajpai, S., 2008, Main Deccan volcanism phase ends at K-T mass extinction: Evidence from the Krishna-Godavari Basin, SE India: Earth and Planetary Science Letters, v. 268, p. 293-311, doi:10.1016/j.eps1.2008.01.015.

Lewenstein, B.V., 1995, From fax to facts: Communication in the cold fusion: Social Studies of Science, v. 25, p. 403-436, doi:10.1177/ 030631295025003001

Lightman, B.V., 2007, Victorian Popularisers of Science: Designing Nature for New Audiences: Chicago, Illinois, University of Chicago Press, 568 p.

Lyell, C., 1830, Principles of Geology: London, John Murray, 532 p.

MacIlwain, C., and Verrell, M., 1994, Comet collision boosts controversy over global protection strategy: Nature, v. 370, p. 165, doi:10 $.1038 / 370165 \mathrm{a} 0$.

Marsden, B.G., 1995, The path to destruction, in Spencer, J.R., and Mitton, J., eds., The Great Comet Crash: The Collision of Comet Shoemaker-Levy 9 and Jupiter: Cambridge, UK, Cambridge University Press, p. 8-18.

McCarthy, P., 1994, Jupiter under bombardment: Sydney Morning Herald, 18 July 1994, p. 1 .

Mcginty, S, 2002, In the line of fire: The Scotsman, 28 June 2002, p. 2.
McLean, D.M., 1985, Deccan Traps mantle degassing in the terminal Cretaceous marine extinctions: Cretaceous Research, v. 6, p. 235-259, doi:10.1016/0195-6671(85)90048-5.

Mellor, F., 2003, Between "fact" and fiction: Demarcating science from nonscience in popular physics books: Social Studies of Science, v. 33, p. 509538, doi:10.1177/0306312703334002.

Mellor, F., 2010, Negotiating uncertainty: Asteroids, risk and the media: Public Understanding of Science (Bristol, England), v. 19, p. 16-33, doi:10.1177/0963662507087307.

Miller, S., 1993, By Jupiter, what a bang: The Independent, 25 October 1993, p. 10.

Nelkin, D., 1987, Selling Science: How the Press Covers Science and Technology: New York, W.H. Freeman and Co., 217 p.

Noble, J.W., 1993, Comet to hit Jupiter with a Texas-sized bang: New York Times, 19 October 1993, p. C1.

Radford, T., 1994, Serial killers from space: The Guardian, 7 July 1994, p. 10.

Rudwick, M.J.S., 1985, The Great Devonian Controversy: The Shaping of Scientific Knowledge among Gentleman Specialists: Chicago, Illinois, University of Chicago Press, 528 p.

Secord, J.A., 2000, Victorian Sensation: The Extraordinary Publication, Reception, and Secret Authorship of Vestiges of the Natural History of Creation: Chicago, Illinois, University Of Chicago Press, 624 p.

Shoemaker, C.S., and Shoemaker, E.M., 1995, A comet like no other, in Spencer, J.R., and Mitton, J., eds. The Great Comet Crash: The Collision of Comet Shoemaker-Levy 9 and Jupiter: Cambridge, UK, Cambridge University Press, p. 7-12.

Sigurdsson, H., D’Hondt, S., Arthur, M.A., Bralower, T.J., Zachos, J.C., van Fossen, M., and Channell, J.E.T., 1991, Glass from the Cretaceous/Tertiary boundary in Haiti: Nature, v. 349, p. 482-487, doi:10.1038/349482a0.

Silverstone, R., 1987, Narrative strategies in television science, in Curran, J., Smith, A., and Wingate, P., eds., Impacts and Influences: Essays on Media Power in the Twentieth Century: London, Methuen and Co., Ltd., p. 291-330.

Smit,J., 1991, Where did ithappen: Nature, v.349, p.461-462, doi:10.1038/349461a0. Spencer, J.R., 1995, The Great Crash, in Spencer, J.R., and Mitton, J., eds., The Great Comet Crash: The Collision of Comet Shoemaker-Levy 9 and Jupiter: Cambridge, UK, Cambridge University Press, p. 55-95.

Sullivan, W., 1974, Continents in Motion: The New Earth Debate: New York, McGraw-Hill, 399 p.

Sullivan, W., 1980, Two New Theories Offered on Mass Extinctions in Earth's Past: New York Times, 10 June 1980, p. C3.

Turco, R.P., Toon, O.B., Ackerman, T.P., Pollack, J.B., and Sagan, C., 1983 , Nuclear winter: Global consequences of multiple nuclear explosions: Science, v. 222, p. 1283-1292, doi:10.1126/science.222.4630.1283.

Turner, A., 1994, BBC-1 Blue Peter, 19 May 1994.

Wainwright, M., 1994, Pigeon fanciers blame Jupiter's big bang as birds go off course: The Guardian, 25 July 1994, p. 3.

Ward, W.C., Keller, G., Stinnesbeck, W., and Adatte, T., 1995, Yucatán subsurface stratigraphy: Implications and constraints for the Chicxulub impact: Geology, v. 23, p. 873-876, doi:10.1130/0091-7613(1995)023<0873 :YNSSIA $>2.3 . \mathrm{CO} ; 2$.

Weise, E., 2008, Crash course in obliterating a danger: USA Today, 8 December 2008, p. 5D.

Weissman, P., 1994, The big fizzle is coming: Nature, v. 370, p. 94, doi: $10.1038 / 370094 \mathrm{a} 0$.

WGBH, 1981, The asteroid and the dinosaur: Nova, 10 March 1981

Wilford, J.N., 1983, Dinosaurs: Catastrophic theory is contested at Hell Hollow: New York Times, 16 August 1983, p. C1.

Wilford, J.N., 1993, Comet to hit Jupiter with a Texas-sized bang: New York Times, 19 October 1993, p. C1.

Williams, A., and Clifford, S., 2009, Mapping the Field: Specialist Science News Journalism in the UK National Media: Cardiff, UK, Cardiff University Press, $82 \mathrm{p}$.

Yeo, R., 1993, Defining Science: William Whewell, Natural Knowledge and Public Debate in Early Victorian Britain: Cambridge, UK, Cambridge University Press, $298 \mathrm{p}$.

Young, R.M., 1985, Darwin's Metaphor: Nature's Place in Victorian Culture: Cambridge, UK, Cambridge University Press, p. 126-165.

Zahnle, K., 1995, Bangs or whimpers?, in Spencer, J.R., and Mitton, J., eds., The Great Comet Crash: The Collision of Comet Shoemaker-Levy 9 and Jupiter: Cambridge, UK, Cambridge University Press, p. 29-37.

ManuscriPt Accepted by the Society 31 January 2014 
Downloaded from specialpapers.gsapubs.org on June 4, 2015 


\section{Geological Society of America Special Papers}

\section{The public impact of impacts: How the media play in the mass extinction debates}

Steve Miller

Geological Society of America Special Papers 2014;505; 439-455, originally published onlineAugust 21, 2014

doi:10.1130/2014.2505(24)

E-mail alerting services

Subscribe

Permission request click www.gsapubs.org/cgi/alerts to receive free e-mail alerts when new articles cite this article

click www.gsapubs.org/subscriptions to subscribe to Geological Society of America Special Papers

click www.geosociety.org/pubs/copyrt.htm\#gsa to contact GSA.

Copyright not claimed on content prepared wholly by U.S. government employees within scope of their employment. Individual scientists are hereby granted permission, without fees or further requests to GSA, to use a single figure, a single table, and/or a brief paragraph of text in subsequent works and to make unlimited copies of items in GSA's journals for noncommercial use in classrooms to further education and science. This file may not be posted to any Web site, but authors may post the abstracts only of their articles on their own or their organization's Web site providing the posting includes a reference to the article's full citation. GSA provides this and other forums for the presentation of diverse opinions and positions by scientists worldwide, regardless of their race, citizenship, gender, religion, or political viewpoint. Opinions presented in this publication do not reflect official positions of the Society.

Notes

(C) 2014 Geological Society of America

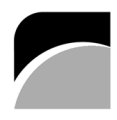

THE GEOLOGICAL SOCIETY OF AMERICA 